En la España Medieval

ISSN: 0214-3038

http://dx.doi.org/10.5209/ELEM.56092

\title{
La clerecía regular ante los conflictos internos y guerras exteriores de la Corona de Castilla durante la Baja Edad Media ${ }^{1}$
}

\author{
Juan Antonio Prieto Sayagués ${ }^{2}$
}

Recibido: 21 de noviembre de 2016 / Aceptado: 15 de marzo de 2017

Resumen. La clerecía regular desempeñó un papel de primer orden en los conflictos de la Castilla bajomedieval. Este artículo analiza el papel de las comunidades religiosas en los conflictos internos y guerras exteriores de la Corona, tanto su presencia en las mismas del lado de uno de los dos bandos en litigio, como su papel de árbitros en las disputas. Abordaremos también la contribución económica de los monasterios y conventos a la causa bélica, así como el papel intercesor que desempeñaron algunos religiosos u objetos litúrgicos albergados en ciertos monasterios. Finalmente, nos referiremos al empleo de los edificios monásticos y conventuales como lugares de refugio y asilo durante las contiendas, la firma de acuerdos en sus muros o su empleo para la construcción de bastidas y otras infraestructuras bélicas necesarias para llevar a cabo las campañas.

Palabras clave: clero regular; conflictos; guerras; Baja Edad Media; Castilla.

\section{[en] The Role of the Regular Clergy in Internal Conflicts and Foreign Wars of the Crown of Castile during the Low Middle Ages}

\begin{abstract}
The regular clergy played a major role in conflicts in Castile during the Lower Middle Ages. This article analyses the part played by religious communities in the internal conflicts and foreign wars affecting the Crown, in terms of their presence on the side of one of the warring parties and their role as mediators in disputes. We will also address the financial contribution of monasteries and convents to the war effort, as well as the interceding role played by some priests or liturgical objects stored in certain monasteries. Lastly, we refer to the use of monastery and convent buildings as places of refuge and shelter during times of conflict, the agreements signed within their walls and their use in the building of fortresses and other military infrastructure needed to carry out campaigns.
\end{abstract}

Keywords: Regular Clergy; Conflicts; Wars; Low Middle Ages; Castile.

Sumario: 1. Introducción. 2. La participación del clero regular en los conflictos y guerras de Castilla. 2.1. El posicionamiento y toma de partido de los religiosos. 2.2. Los religiosos: árbitros en las disputas internas de la Corona. 3. Las prestaciones económicas para la casus belli de monasterios y conventos. 3.1. Las aportaciones económicas en los conflictos internos de Castilla. 3.2. Las contribuciones económicas en las guerras exteriores castellanas. 4. El papel de los monasterios como intercesores en la batalla. 5. Las infraestructuras monásticas: refugios, bastiones y firma de acuerdos. 5.1. Lugares de residencia provisional y asilo. 5.2. La celebración de Cortes, treguas y acuerdos de paz. 5.3. Los edificios monásticos y la infraestructura castrense. 6. Conclusiones.

1 El presente trabajo forma parte del Proyecto de Investigación coordinado "Poderes, espacios y escrituras en los reinos occidentales hispánicos (ss. XI-XIV)", ref. HAR2013-42925-P, financiado por el MINECO.

2 Investigador predoctoral FPU en el Departamento de Historia Antigua y Medieval de la Universidad de Valladolid. Universidad de Valladolid

juanantonio.prieto@uva.es 
Cómo citar: Prieto Sayagués, J.A. (2017) La clerecía regular ante los conflictos internos y guerras exteriores de la Corona de Castilla durante la Baja Edad Media, en En la España Medieval 40, 309-337.

\section{Introducción}

Como ya pusieron de manifiesto Nieto Soria y Villarroel González, los eclesiásticos no fueron ajenos a las guerras y conflictos que asolaron Castilla a lo largo de la Baja Edad Media, sino que estuvieron inmersos en la dinámica política del reino. Ambos autores han centrado su estudio principalmente en la jerarquía eclesiástica secular advirtiendo que la participación de los eclesiásticos tuvo lugar más bien a título individual y no como resultado de una dinámica estamental ${ }^{3}$. En la misma línea se sitúa el trabajo de González Sánchez acerca de la participación de algunos eclesiásticos del clero secular castellano en las campañas de Fernando de Antequera, primero como infante de Castilla y después como rey de Aragón ${ }^{4}$. Con estos precedentes, en este trabajo nos centraremos en exclusiva en el papel desempeñado por el clero regular en dichos conflictos.

Ante esta situación que acabamos de exponer algunas órdenes religiosas trataron de poner freno a la participación de los religiosos en dichos conflictos; sirva como ejemplo las órdenes dadas en el Capítulo General celebrado en Provenza (1276) por la Orden de los Predicadores:

ordenamos no unirnos a las guerras entre los príncipes, las sentencias de los prelados y en las negociaciones entre las comunidades. Que todos los frailes se abstengan de hablar imprudentemente de los negocios, principalmente delante de los $\operatorname{laicos}^{5}$.

Pese a estas prescripciones, en este estudio mostraremos como la participación de los regulares en labores bélicas en Castilla fue significativa durante el periodo bajomedieval; de hecho, según señala Miura Andrades, la intervención de los religiosos en las campañas militares organizadas por los monarcas fue un vía de acceso a la privanza regia ${ }^{6}$. Dicha participación de los eclesiásticos en los conflictos de la Corona dio lugar a quejas por parte de los estamentos como las expresadas en algunas reuniones de Cortes. Así, en las de Toledo de 1462 entre las quejas expresadas en el cuaderno de Cortes se encuentra "que algunos obispos e abades e otras personas eclesiásticas se han fecho e de cada día se fazen de vandos, e algunos dellos tanto e más escandalizan vuestras çibdades e villas que los legos dellas"

3 Nieto Soria, Iglesia y génesis; Villarroel González, "Servir al rey en las ligas nobiliarias”, pp. 751-781. En palabras de Nieto Soria, "una línea de investigación de la historia bajomedieval castellana hasta la fecha inexplorada es aquella que se refiere al estudio de la proyección política que alcanzaron algunas de las órdenes religiosas más significativas del momento, constituyendo, por tanto, tal cuestión un apartado dentro del estudio de la indudable significación política de la Iglesia en los tiempos medievales, tanto desde su perspectiva individual como institucional", en Nieto Soria, "Franciscanos y franciscanismo", p. 109.

4 González Sánchez, "La participación de los eclesiásticos”, pp. 269-304.

Paul, "Les frères Prêcheurs", pp. 33-37.

Miura Andrades, Frailes, monjas y conventos, p. 85.

RAH, Cortes de los antiguos reinos de León y Castilla, Tomo III, Imprenta de M. Rivadeneyra, Madrid, 1866, pp. 711-712. 


\section{La participación del clero regular en los conflictos y guerras de Castilla}

\subsection{Posicionamiento y toma de partido de los religiosos}

Durante la Baja Edad Media las diferentes órdenes religiosas y varios miembros de sus comunidades tomaron partido y se posicionaron en favor de alguno de los bandos en litigio. En los casi dos siglos que transcurrieron desde la turbulenta sucesión al trono del rey Sabio hasta los conflictos acaecidos entre Enrique IV y la nobleza, nos encontramos a diversos religiosos tomando diferentes posturas en los mismos.

Durante los conflictos derivados de la sucesión al trono de Alfonso X y, movido por motivos políticos, antes de la primavera de 1282 el infante Sancho reunió en Valladolid a los abades de las tres grandes órdenes monásticas del momento: cluniacenses, cistercienses y premonstratenses. En torno a unos cuarenta acudieron a la llamada cuya conclusión fue la organización de una hermandad con el fin de lograr una mayor protección del infante contra los desafueros que se cometían contra sus derechos ${ }^{8}$. Sin embargo, el motivo real por parte del infante era granjearse el mayor número de apoyos posibles para su causa ${ }^{9}$. A través de dos documentos de 1282 relativos a la Hermandad, podemos conocer el carácter político de la misma. En dichos documentos se contienen algunas cláusulas clarificadoras como las siguientes:

Que por los muchos desafueros, daños, fuerzas, muertes y despechamientos sin ser idos, deshonras y otras muchas cosas descomedidas que eran contra Dios, la justicia y gran perjuicio del reino, que habia hecho el rey don Alonso, se habian juntado de orden del infante don Sancho, su señor, los infantes, prelados, ricos-hombres, concejos, ordenes y caballeria de los reinos de Castilla, Leon y Galicia [...]

Los primero que guardemos e mantengamos el señorio de nuestro señor el ynffant don Sancho e de los reyes que despues del vernan ${ }^{10}$

Si las antiguas órdenes monásticas estuvieron presentes en este conflicto, como acabamos de señalar, las nuevas órdenes mendicantes no fueron la excepción. En la reunión de Valladolid de 1282, parece ser que también se encontraba presente el provincial dominico fray Munio de Zamora ${ }^{11}$. La labor desempeñada por este fraile durante los años del conflicto sucesorio y tras el ascenso al trono de Sancho IV no sería olvidada por el monarca, quien intercedió en favor del religioso en varios momentos

8 De la Cruz, La abadía cisterciense de Bujedo, p. 147; Cañas Gálvez, El itinerario de la corte de Juan II, p. 145. Esta Hermandad la hicieron los monasterios de Oña, Arlanza, Silos, San Millán, Cardeña, Montes, San Prudencio, Valverde, Santa María de Vega, la Vid, San Pelayo de Hornillas, Villoria, Villamediana, Medina del Campo, San Miguel del Monte, Valbuena, la Espina, Valparaiso, Moreruela, Matallana, Palazuelos, San Pedro de Gomello, Sandoval, Valdeiglesias, Aguilar, Retuerta, San Pelayo de Cerrato, Santa Cruz de Monzón, Villamayor, San Cristóbal de Bujedo, San Leonardo de Alba de Tormes y Sancti Spiritus de Alba, en Martínez Liébana, El dominio señorial, p. 637; Escalona, Historia del real monasterio, p. 156. También resulta de interés señalar las ausencias en la Hermandad de varios monasterios cistercienses, premonstratenses y benedictinos, orden esta última, que aportó muy pocos monasterios a la misma. Entre las ausencias sobresalen los monasterios benedictinos de San Zoilo de Carrión, San Isidro de Dueñas, San Román de Entrepeñas, Santa María la Real de Nájera, Obarenses, San Salvador de Cornellana, entre los cistercienses, tampoco asistieron San Martín de Castañeda, San Vicente de Segovia, Herrera, Rioseco, Belmonte, Valdedios y Villanueva de Oscos; de los premonstratenses se observa la ausencia de Brazacorta, además de algunos monasterios gallegos de dichas órdenes en Fernández Martín, Luis, "La participación de los monasterios”, pp. 11-16.

9 Nieto Soria., Sancho IV, p. 45.

10 Fernández Martín, "La participación de los monasterios”, pp. 11-16.

11 Álvarez Rodríguez, Conventos y sociedad urbana, pp. 173-174. 
delicados de su vida ${ }^{12}$. Por lo que respecta a la otra gran orden mendicante del momento, los franciscanos, se desconoce la postura que tomó en esta revuelta el consejero del infante Sancho, el custodio de Zamora y después provincial de Santiago fray Juan Gil de Zamora. Sin embargo, en su obra De preconiis Hispaniae ensalzó a Sancho, a quien el religioso deseaba una larga vida y un próspero reinado, por lo que probablemente también le prestara su apoyo en momentos anteriores ${ }^{13}$. Otro ejemplo de la participación mendicante en el conflicto sucesorio de Alfonso X lo encontramos en la investigación llevada a cabo por Pedro Sánchez de Monteagudo el 14 de abril de 1284, con la finalidad de dilucidar la posible colaboración del guardián de San Francisco de Burgos en la revuelta del infante Sancho contra su padre. Puede que en la misma también estuviese implicado el obispo franciscano de la ciudad, quien lo negó y protestó contra su imputación ${ }^{14}$. Otro obispo salido de la clerecía regular que parece ser que también estuvo del lado del infante Sancho fue el arzobispo de Santiago y Canciller Mayor, fray Rodrigo, al que el nuevo monarca se dirigía frecuentemente como aquel "que siempre fue e es a mio servicio", alocuciones que nos pueden estar informando del apoyo a su causa durante el conflicto sucesorio ${ }^{15}$.

Más de medio siglo después, en la Guerra de los Dos Pedros el monasterio de Sahagún aportó ballesteros al rey castellano. El 4 de junio de 1362 Pedro I mandaba al abad que enviase veinte ballesteros de los mejores que tuviese ${ }^{16}$ y el 29 de agosto de 1364 ordenaba a la villa de Sahagún enviar otros treinta. Ante la petición regia el concejo y el abad establecieron una nueva alcabala que gravaba el vino, mosto y vinagre que se vendía en la villa para pagar el sueldo de dichos ballesteros. Surgieron algunos problemas, por lo que el 4 de noviembre de 1364 Pedro I ordenó al concejo de Sahagún que no se reclutasen entre los ballesteros a vasallos excusados del abad, ante las quejas de este último de que así se había hecho ${ }^{17}$; poco tiempo después, el monarca mandaba al concejo de Mayorga que no tomara por ballesteros a los de Saelices por el mismo motivo ${ }^{18}$. Otro religioso que participó en dicha contienda, que con el tiempo se entremezcló con la guerra civil castellana, fue el obispo dominico de Lugo y confesor de Pedro I, Pedro López de Aguiar, quien en el conflicto dinástico se enfrentó contra los partidarios de Enrique de Trastámara ${ }^{19}$. En el bando contrario pudieron estar los franciscanos, si tenemos en cuenta las donaciones y privilegios que recibieron los conventos de la orden, principalmente aquellos situados en las regiones afectadas por la contienda civil ${ }^{20}$; algo similar se puede decir del abad de Bujedo de Juarros quien se encontraba junto a

12 Además del presumible apoyo prestado por fray Munio al infante Sancho durante el conflicto sucesorio, el dominico también jugó un papel de primer orden en otros asuntos durante el reinado de Sancho IV, como participar en la falsificación de la bula de dispensa matrimonial para el monarca y María de Molina, en Linehan, La Iglesia española, pp. 196-209.

13 Rojo Alique, "Intelectuales franciscanos", p. 308.

14 García Oro, Francisco de Asis, p. 337.

15 Nieto Soria, Iglesia y poder real, p. 37.

16 Martínez Liébana, El dominio señorial, p. 673.

17 VV. AA., Colección diplomática, no 2415; Díaz Martín, Colección documental de Pedro I, no 1291.

18 La fecha de la orden es el 20 de enero de 1365, en Díaz Martín, Colección documental de Pedro I, $\mathrm{n}^{\circ} 1.300$. Una vez finalizada la guerra civil castellana el monasterio benedictino de Sahagún siguió contribuyendo a la causa bélica de la nueva dinastía, como cuando en 1373 el abad permitió que sus excusados aportaran por una vez, el pago y transporte de 40 cargas de trigo para el ejército del rey, en VV. AA., Colección diplomática, ${ }^{\circ} 2476$.

19 Manso Porto, "El obispo fray Pedro López de Aguiar", p. 43.

20 Nieto Soria, "Franciscanos y franciscanismo", p. 110. 
sus hombres en el Real de Toledo instalado por Enrique II a comienzos de $1369^{21}$.

Tras los precedentes que acabamos de señalar, fue en las Cortes de Valladolid de 1385 cuando el segundo Trastámara, Juan I, por primera vez en una reunión de este tipo pidió oficialmente a los eclesiásticos que contribuyeran con las armas en la causa bélica mostrándose contundente:

Commo todos los ommes deven estar armados de armas espirituales para se defender delas asechanzas del diablo segunt la Santa Escritura, bien así los que an guerra deven estar armados de armas tenporales para sse defender de sus enemigos e para conquistar por la ayuda de Dios. Por ende ordenamos e mandamos que todos los de los nuestros regnos así clérigos como leygos, e de qualquier ley o condiçión que sean, que ayan de veynte annos arriba e de sesenta ayuso, sean tenudos de aver e tener armas ${ }^{22}$.

Las turbulencias del siglo XIV no cesaron en la siguiente centuria ni tampoco la participación de la clerecía regular en las mismas, sino todo lo contrario. En el siglo $\mathrm{XV}$, durante los conflictos internos del reinado de Juan II, nos encontramos a varios religiosos inmersos en los mismos. En algunos casos los religiosos colaboraron con la nobleza levantisca, como pone de manifiesto la actuación de Fadrique de Luna, quien junto a varios caballeros sevillanos trataron de apoderarse del castillo de Triana y las Atarazanas y sublevar Andalucía a favor de los infantes de Aragón. Se llevó a cabo una investigación secreta que tuvo como resultado que el 9 de marzo de 1434 fueran ejecutados varios nobles en Medina del Campo; sin embargo, en el caso de un fraile franciscano portugués, también implicado en los hechos, el castigo fue menor: cárcel perpetua ${ }^{23}$.

Otros religiosos, principalmente dominicos, prestaron su apoyo a la causa regia frente a las sublevaciones de los nobles ${ }^{24}$. En la ciudad de Cuenca hubo una gran conflictividad en el siglo XV. Los Mendoza fueron uno de los linajes que trataron de hacerse con el control del concejo y con el apoyo regio fueron nombrados guardas mayores de la ciudad. Sin embargo, en el conflicto mantenido entre Juan II y los infantes de Aragón, esta familia nobiliaria se posicionó a favor de los segundos. El obispo dominico Lope de Barrientos participó en la defensa de Cuenca a favor del rey contra Diego Hurtado de Mendoza y sus aliados dirigiendo las tropas concejiles entre 1447 y 1449. El 30 de mayo de 1447, el rey nombró a Lope de Barrientos guarda mayor de la ciudad en detrimento de los Mendoza para afianzar la situación del obispo dominico en la ciudad ${ }^{25}$. Cuando la situación se complicó para el monarca y viendo que perdía la ciudad, hizo un trato con Diego Hurtado de Mendoza entregándole el lugar de Cañada a cambio de que el noble cediera al rey el castillo

\footnotetext{
De la Cruz, La abadía cisterciense de Bujedo, p. 154.

RAH, Cortes, II, p. 315.

Porras Arboledas, Juan II, p. 192; Nieto Soria, "Franciscanos y franciscanismo", p. 111.

24 Como ya señalamos en otros trabajos, en términos generales, los conventos y comunidades dominicas mantuvieron unas estrechas relaciones con la monarquía alcanzando el cénit de dichos vínculos durante el reinado de Juan II (1406-1454); de manera paralela, durante este mismo periodo la nobleza se decantó más por otras órdenes religiosas, particularmente por la orden franciscana en sus vertientes masculina y femenina -clarisas-, en Prieto Sayagués, "El acercamiento de la monarquía castellana”, pp. 197-224; Prieto Sayagués, "La relegación de la orden franciscana", pp. 819-832.

25 Villarroel González, "Eclesiásticos al servicio regio", pp. 21-25.
} 
de Cuenca ${ }^{26}$. El dominico también participó en la batalla de Olmedo aportando en torno a ciento veinte hombres de armas, desempeñó un papel crucial en favor de los conversos en los sucesos protagonizados por el alcalde mayor de Cuenca, Pedro Sarmiento ${ }^{27}$ y fue uno de los principales instigadores del alejamiento de Juan II y el príncipe Enrique ${ }^{28}$. Otro dominico jugó un papel crucial en Toledo. Fray Pedro de Silva, hermano del I conde de Cifuentes y alférez real, Juan de Silva, tuvo un destacado papel en esta ciudad en favor de Juan II durante el enfrentamiento con su hijo, el príncipe Enrique, como nos indica la crónica del obispo dominico Juan López

bastó él (fray Pedro de Silva) para introducir al rey en el convento una noche y después por su persuasión se redujeron los principales caballeros de aquella ciudad deudos suyos al gobierno del rey y se apartó del servicio de su hijo el príncipe don Enrique ${ }^{29}$.

Sin embargo no todos los dominicos defendieron la causa regia. Poco tiempo después, otro fraile de la Orden de los Predicadores protagonizó un episodio relacionado con las tensiones del momento, pero en este caso no lo hizo del lado del monarca y de su valido, Álvaro de Luna, sino expresando los deseos del bando nobiliario. El Viernes Santo de 1453 la Corte se encontraba en Burgos y cuando Álvaro de Luna, su criado Alonso Pérez de Vivero y Fernando de Rivadeneyra llegaron a la catedral para asistir a la liturgia encontraron al rey "delante del monumento, dentro de sus cortinas, oyendo el sermón de aquel día, el qual ya era començado, e predicábale un fraile de la Orden de los Predicadores". Este fraile, instigado por Pérez de Vivero, recibió una dura reprimenda del rey quien lo mandó callar por sus críticas a Álvaro de Luna, aunque en su sermón no hiciera alusión expresa al mismo. Inmediatamente el Maestre se quejó al obispo -quien metió preso al fraile en la cárcel episcopal- y asesinó también a su cómplice Pérez de Vivero exhortado por Fernando de Ribadeneyra ${ }^{30}$.

Durante el reinado de Juan II nos encontramos a un religioso -en este caso franciscano- colaborando con las autoridades para evitar la conquista de una plaza cristiana por el enemigo musulmán. El guardián del convento de San Francisco de Jerez avisó al corregidor de la villa de las intenciones de dos habitantes de la misma de vender Jerez a los nazaríes granadinos. Los hechos habían llegado a oídos del religioso gracias a la confidencia de un musulmán que quería convertirse a la religión cristiana ${ }^{31}$.

Cuando Enrique IV llegó al trono no consiguió traer la paz a Castilla, sino que la conflictividad interna siguió siendo la tónica predominante. Los enfrentamientos entre la nobleza y los partidarios del monarca llegaron a su culmen con su deposición y el nombramiento como rey de Castilla del hermanastro de Enrique IV, el infante Alfonso.

26 Díaz Ibáñez, "Iglesia, nobleza”, p. 232; Pérez de Guzmán y Galíndez de Carvajal, Crónica, pp. 524-526; Palencia, Gesta Hispaniensia, pp. 59-60.

27 Martínez Casado, Lope de Barrientos, pp. 39 y 49-53.

28 Nieto Soria, Iglesia y génesis, p. 267.

29 López, Tercera parte, p. 162. Años después, este mismo religioso trató, a través de su hermana María de Silva - esposa de Pero López de Ayala, alcalde mayor de Toledo- la entrada del monarca en dicha ciudad, en Nieto Soria, Iglesia y génesis, p. 279.

30 Prieto Sayagués, "El acercamiento de la monarquía", p. 211; Cañas Gálvez, El itinerario de la corte de Juan II, p. 71; Sin embargo, detrás de la muerte de Vivero también estaban el príncipe Enrique, la reina Isabel de Portugal y su camarera mayor Beatriz de Estúñiga, en Nieva Ocampo, "De la colaboración a la oposición", p. 97.

31 Sancho de Sopranis, “San Francisco el Real de Jerez”, pp. 382-383; García Oro, Francisco de Asís, p. 427. 
Ante estos acontecimientos la clerecía regular no se mantuvo al margen. Además de algunos frailes que mantuvieron una postura neutral, como el obispo franciscano de Ciudad Rodrigo, Alfonso de Palenzuela ${ }^{32}$, otros religiosos se implicaron en el conflicto apoyando a uno de los dos bandos, bien comunidades enteras a título corporativo, bien algunos miembros de las mismas a título individual.

El dominico Juan López defendió la causa del príncipe Alfonso, lo cual no es de extrañar si tenemos en cuenta que era el confesor de los condes de Plasencia, participantes en la deposición en efigie de Enrique IV en la Farsa de Ávila ${ }^{33}$. El infante Alfonso contó también con el apoyo de otro importante religioso dominico. Nos estamos refiriendo a fray Alonso de Burgos, fraile de San Pablo de Burgos y Valladolid a quien el infante-rey conoció en junio de 1465 durante una visita a esta última villa; fue en ese momento cuando el religioso obtuvo el permiso para acompañar al nuevo monarca en su lucha contra Enrique IV. Según narra el cronista Palencia, fray Alonso también participó en la batalla de Olmedo junto a las tropas del infante Alfonso ${ }^{34}$. Otros de los religiosos que estuvieron del lado del infante Alfonso fueron fray Rodrigo de Mesa, prior del Parral y el agustino fray Martín de Córdoba. El primero de ellos mostró su apoyo al infante ayudando al obispo de Segovia y a su hermano para entregar la ciudad al marqués de Villena en contra de Enrique IV; por su parte, el fraile agustino expresó sus simpatías a través de otros cauces, como las alocuciones favorables contenidas en su obra ${ }^{35}$. En el bando contrario nos encontramos al dominico fray Alonso de Fuensalida, a quien Pedro Girón, maestre de Calatrava desposeyó de la tenencia de la ermita de Santa María de Gracia en Carmona "por apoyar al depuesto rey don Enrique"; en su lugar designó a fray Juan de Soosa, el 9 de agosto de $1465^{36}$. Otras comunidades de religiosos y religiosas se posicionaron corporativamente a favor de uno de los dos bandos. El monasterio de Santo Domingo el Real de Toledo debió de estar del lado del príncipe Alfonso, como ponen de manifiesto varios documentos fechados entre el 16 de julio de 1466 y el 7 de abril de 1467, en los que manda entregar al monasterio cosas contenidas en privilegios anteriores ${ }^{37}$. Igualmente, en el convento dominico de Sevilla ya se intrigaba a inicios de dicho año para deponer a Enrique IV, siendo algunos de los conspiradores expulsados de la ciudad ${ }^{38}$.

En medio de la inestable situación política, el 18 de marzo de 1467 se produjo un concierto entre el concejo de Tordesillas y el convento de Santa Clara ante el rumor de que Alonso de Fonseca, arzobispo de Sevilla, atacase la villa para arrebatársela a Enrique IV. Los vecinos de Tordesillas pidieron a Ruy Vázquez y a Juan Vázquez que rogasen a la abadesa clarisa en nombre del concejo para que enviase a algunos de sus vasallos en ayuda de la defensa de la villa ${ }^{39}$. Se trataba de un acuerdo entre la comunidad de religiosas y el concejo para evitar daños contra la villa y el propio mo-

\footnotetext{
Nieto Soria, "Franciscanos y franciscanismo", p. 112.

33 Castro y Castro, El Real Monasterio, p. 154; Prieto Sayagués, "El acercamiento de la monarquía", p. 216; Nieva Ocampo, "De la colaboración a la oposición", p. 98. Este religioso reprochó en sus escritos a Enrique IV sus costumbres arábigas y su cercanía a los mudéjares y conversos, en Nieva Ocampo, "La Observancia dominica", p. 515.

34 Olivares Martínez y Palomo Fernández, "Escudos con flor”, pp. 94-96; Prieto Sayagués, "El acercamiento de la monarquía", p. 216; Nieva Ocampo, "De la colaboración a la oposición”, p. 97.

35 Nieto Soria, Iglesia y génesis, p. 284.

36 Miura Andrades, Frailes, monjas y conventos, p. 92.

37 Cañas Gálvez, Colección diplomática, $\mathrm{n}^{\circ}$ 257-260.

38 Miura Andrades, Frailes, monjas y conventos, p. 92.

39 Castro Toledo, Colección diplomática, $\mathrm{n}^{\circ} 776$.
} 
nasterio. El documento es una muestra clara sobre del poder que ejercían las clarisas, quienes ante la orden de la abadesa enviaron a varios de sus vasallos de San Miguel del Pino para guardar las torres que la religiosas tenía en dicha villa ${ }^{40}$.

Después de todo lo señalado hemos podido observar como la participación de los religiosos en las contiendas internas y guerras exteriores de Castilla durante la Baja Edad Media no fue algo esporádico, sino que a medida que avanzaba el tiempo, esta fue aumentando con una mayor implicación en las mismas. Pocas órdenes se vieron exentas de tomar partido en los diferentes conflictos, destacando en este aspecto los mendicantes, principalmente dominicos. También se aprecia una disminución progresiva de la participación en las contiendas de las órdenes tradicionales -benedictinos, cistercienses y premonstratenses-, que tan importante papel desempeñaron en los estadios iniciales del periodo de estudio, durante el conflicto sucesorio de Alfonso X. Finalmente, aunque de forma mucho más reducida, también actuaron de manera activa en dichos conflictos algunos religiosos de otras órdenes como agustinos y jerónimos.

\subsection{Los religiosos, árbitros en las disputas internas de la corona}

Además del apoyo a la causa de los contendientes de uno u otro bando los religiosos también participaron en los conflictos situándose en una posición intermedia, como parte neutral, desempeñando la función de árbitros en algunos de los litigios. En muchas de las ocasiones ejercieron dicho papel ante la petición de los poderes seglares, quienes confiaban en la vida ejemplar y santidad de algunos de los más reputados frailes y monjes castellanos.

Hacia 1427 los nobles se habían reunido en Valladolid para pedir al rey que alejase de la Corte a su privado, Álvaro de Luna, a lo que aquél se oponía ${ }^{41}$. Juan II, aconsejado del franciscano Francisco de Soria, puso esta contienda bajo el arbitrio de cuatro jueces y, en caso de discordia, sería el prior de San Benito de Valladolid, fray Juan de Acevedo, quien habría de resolver en un plazo de diez días ${ }^{42}$. Al no llegarse a un acuerdo, fray Juan de Acevedo tras celebrar una misa en presencia de los cuatro compromisarios tomó en sus manos la Sagrada Forma con la que les exhortó a que dijeran la verdad ${ }^{43}$. La sentencia fue que el condestable tenía que partir de Simancas en un plazo de tres días sin encontrarse antes con el rey, prohibiéndosele entrar en la Corte ni a quince leguas de la misma durante un año y medio. Ante dicha sentencia Álvaro de Luna se retiró a su villa de Ayllón ${ }^{44}$.

En otras ocasiones, aunque no se trataba de arbitrar ninguna situación en concreto, los religiosos trataron de interceder y de mediar entre las partes en conflicto para lograr la pacificación. Ésto fue lo que ocurrió en 1439 cuando el rey estaba en Roa, en el contexto de la rebelión del adelantado mayor Pedro Manrique y el almirante Fadrique, a donde se presentaron algunos religiosos para pedirle la paz en Castilla; entre ellos se encontraban varios monjes de San Benito de Valladolid y Guadalupe, además del provincial mercedario fray Simón de Camargo y otros religiosos jerónimos, cartujos y mercedarios. El provincial mercedario es presentado por el cronista

\footnotetext{
40 Rodríguez Guillén, El monasterio, pp. 73-74.

41 Rodríguez Martínez, Historia del monasterio, p. 109.

42 Salazar y Castro, Historia genealógica, II, pp. 23-24; Layna Serrano, Historia de Guadalajara, p. 177.

43 Rodríguez Martínez, Historia del monasterio, p. 109.

44 Layna Serrano, Historia de Guadalajara, p. 177; Rodríguez Martínez, Historia del monasterio, p. 110.
} 
de la orden como un fiel defensor de la autoridad real, tratando que los rebeldes devolvieran la obediencia al monarca e informando a este último de la postura de los sublevados. El religioso indicó a Juan II que el blanco de aquéllos era el condestable Álvaro de Luna y que sólo le pedían que gobernase por sí mismo y, en caso de tener que confiar el gobierno del reino a alguien, éste fuera su hijo, el infante Enrique ${ }^{45}$. Tras entablar las conversaciones con el monarca se dirigieron a Medina de Rioseco para hacer lo propio con la facción contraria y reunirse con el almirante y con varios nobles y caballeros de su parcialidad. Sin embargo, en este caso la voluntad de los religiosos no obtuvo los resultados esperados y en vistas a la respuesta se vieron obligados a regresar a sus monasterios ${ }^{46}$. Llama la atención que no se halle presente entre la nómina de religiosos ningún franciscano, quizás debido a que durante estos años dicha orden estaba vinculada a diferentes linajes de la nobleza castellana ${ }^{47}$.

Cuatro años después de los hechos descritos, el enfrentamiento entre el bando regio y la liga nobiliaria se encontraba en uno de los momentos más álgidos con el secuestro del monarca. En este contexto se enmarca el acuerdo alcanzado el 15 de noviembre de 1443 en Sevilla entre el conde de Niebla, Juan de Guzmán, el adelantado Per Afán de Ribera, Pedro de Guzmán y el prior de la cartuja de Las Cuevas de Sevilla, fray Fernando de Torres. En el se comprometían a defenderse entre sí y a amparar la autoridad real, prohibiéndose hacer otras confederaciones sin autorización del resto. Este acuerdo reflejaba las acciones llevadas a cabo en ese momento por el infante Enrique en Andalucía, que no iban dirigidas a preservar ni la autoridad ni la soberanía regia ${ }^{48}$. Durante el reinado de Enrique IV, el prior cartujo también fue el encargado de mediar en el enfrentamiento entre las ciudades de Sevilla y Carmona, pacificó al duque de Medina Sidonia Juan de Guzmán y al conde de Arcos, Juan Ponce de León por mandato regio y sosegó la discordia entre el monarca y Pío II. En 1473, en medio de los enfrentamientos sevillanos entre el duque de Medina Sidonia y el marques de Cádiz, el dominico fray Diego Godoy, prior de Santo Domingo de Écija y San Pablo de Sevilla, logró alcanzar una tregua entre el duque y el marqués, por cuyos trabajos recibió del concejo 12.000 maravedís $^{49}$.

El jerónimo fray Alonso de Oropesa también realizó una importante labor pacificadora entre la alta nobleza y el rey en las cortes de Medina del Campo, participando activamente como juez y árbitro ${ }^{50}$. En 1463, en el capítulo privado para la elección de un nuevo general de los jerónimos, además de ser reelegido fray Alonso de Oropesa por otro periodo de seis años, se le permitió que acudiera a dichas Cortes ante el llamamiento del monarca; al fraile se le encomendaron asuntos que atañían al reino, especialmente la anulación del nombramiento de maestre de Santiago realizado en

45 "Escuchó con gusto el rey lo que dezía con sinceridad de ánimo el siervo de Dios; tomó su consejo y dando instrucciones de todos su ministros quedó acordado todo un congreso que el Rey y los Confederados tuvieron en Castronuño. Con esto cesaron las armas, se precavieron las hostilidades, reformaron sus gentes entregaron al rey sus plazas y castillos que con violencia le avían tomado, con que quedó sosegado todo”, en Vega y Toraya, Chronica, pp. 255-257.

46 Pérez de Guzmán y Galíndez de Carvajal, Crónica, p. 389; Nieto Soria, Iglesia y génesis, p. 270.

47 Prieto Sayagués, Juan Antonio, "La relegación de la orden franciscana por parte de la monarquía y su repunte en los ambientes nobiliarios durante el reinado de Juan II de Castilla", en Manuel Pérez del Rosal (coord.), El franciscanismo: identidad y poder. Libro homenaje al P. Enrique Chacón Cabello, OFM, Córdoba: Asociación Hispánica de Estudios Franciscanos-Universidad Internacional de Andalucía, 2016, pp. 819-832.

48 Villarroel González, "Servir al rey en las ligas nobiliarias", pp. 768-769.

49 Cantera Montenegro, "Las relaciones de las cartujas", p. 281.

50 Martínez Medina y Martín Biersack, Fray Hernando de Talavera, p. 21. 
favor de Beltrán de la Cueva y del juramento de heredera en Juana la Beltraneja, y que se concediesen ambas al hermano del rey, el infante-rey Alfonso ${ }^{51}$. Un año después, el 30 de noviembre de 1464 Enrique IV y los prelados y nobles del reino tuvieron una reunión entre Cabezón y Cigales para nombrar cuatro personas que estuviesen en Medina del Campo y determinasen en lo que propusieran al rey y los grandes del reino. Fueron elegidos Pedro Fernández de Velasco, Gonzalo de Saavedra, Álvaro de Estúñiga, Juan Pacheco y en caso de discordia intervendría fray Alonso de Oropesa "e lo quel dicho padre general con la mayor parte de los dichos deputados o con dos dellos dixere o declarara que es justiçia e rason que aquello aya de ser cumplido e esecutado" 52 . El jerónimo era un firme defensor del bando realista, además de por la cercanía a Enrique IV, por ciertos comportamientos de la nobleza levantisca contrarios a la orden, como su pretensión de convertirla en una orden militar $^{53}$. Ante la labor del fraile no se hace extraño que cuando Enrique IV concedió 30.000 maravedís a Lupiana el 7 de diciembre de 1464, expusiese entre sus motivos

acatando e considerando los muchos e buenos servicios que el reverendo padre frey Alfonso de Oropesa padre general de la Orden de San Geronimo me ha fecho y faze de cada dia en especial en lo que ha trabajado y trabaja continuamente en la paz y sosiego y tranquilidad de los mis reynos e en el bien de la cosa publica dellos ${ }^{54}$.

Los enfrentamientos entre el rey y la nobleza, también tuvieron su proyección en el seno mismo de las ciudades castellanas. Durante este periodo se agudizaron las luchas banderizas y enfrentamientos entre los principales linajes de las urbes. Éstas mantenían a Jerez en la década de los sesenta del siglo XV en una situación insostenible. Ante los enfrentamientos que tuvieron lugar en dicha villa, fray Juan de Rota, guardián del convento de San Francisco de dicha villa y fray Pedro de San Salvador se presentaron en el concejo y pidieron se tomaran medidas para la pacificación de la urbe. El concejo, tras agradecer su preocupación por fomentar y mantener la paz, acordó que se informase al maestro fray García de Vargas, prior de Santo Domingo, a fray Miguel, al comendador de la Merced, fray Antón de Jerez y a fray Juan de Fonseca "que eran personas nobles y honestas y religiosas y deseosas de paz y concordia" y tras ello, acordó la pacificación de los bandos de la ciudad ${ }^{55}$. No vamos a extendernos más en la participación de algunos religiosos en los conflictos banderizos ocurridos en las urbes, cuestión a la que ya dedicamos unas páginas en otro trabajo ${ }^{56}$.

Al contrario que ocurría en la toma de partido por uno de los bandos en litigio por parte de los religiosos -en los que hemos observado la primacía de dominicos y franciscanos-, cuando se trató de intermediar fueron los benedictinos de Valladolid, jerónimos y cartujos quienes encabezaron la nómina de árbitros en los conflictos. En

\footnotetext{
1 Díaz y Díaz, “Alonso de Oropesa”, p. 257.

52 Palencia, Gesta Hispaniensia, p. 295; González Crespo, Elevación de un linaje, Apéndice Documental, nº 79; Sigüenza, Historia de la Orden, pp. 445-447.

53 Romero Fernández-Pacheco, El monasterio, p. 13.

${ }_{54}$ Archivo Histórico Nacional (en adelante AHN), Clero secular-regular, Pergaminos, Carp. 578, $\mathrm{n}^{\circ} 18$.

55 Miura Andrades, Frailes, monjas y conventos, pp. 92-94; Sancho de Sopranis, "San Francisco el Real de Jerez", pp. 385-387.

56 Prieto Sayagués, "La función sociopolítica", pp. 423-425.
} 
el caso de los arbitrajes parece que pesó más el hecho de la vida ejemplarizante de todas estas órdenes cuyo elemento común fue el estricto cumplimiento de la regla y la Observancia. Asimismo, en el ejemplo de Jerez se pone de manifiesto que más que la confianza en una determinada orden religiosa, lo que prevalecía era la fama que tenían en la ciudad ciertos religiosos profesos en distintos monasterios.

\section{Las prestaciones económicas para la casus belli de monasterios y conventos}

\subsection{Las aportaciones económicas en los conflictos internos de Castilla}

En el anterior apartado hemos hecho referencia a la participación política de los religiosos en los conflictos internos y guerras externas de Castilla. Sin embargo, su papel en los mismos no se redujo sólo a ello, sino que también contribuyeron en cuestiones económicas con las empresas bélicas.

Cuando el hijo y sucesor de Sancho IV subió al trono contaba con nueve años de edad, ante lo que surgieron diversos conflictos entre los familiares del rey niño por hacerse con las riendas del gobierno de Castilla. En estos problemas, también se vieron inmersos los religiosos: Bernardo de Blanesto, prior de San Isidro de Dueñas, colaboró con el infante Juan, quien por entonces se reclamaba rey de León, acuñando moneda. El infante ordenó acuñar moneda en Dueñas -villa que estuvo en sus manos hasta 1299 en que fue recuperada por los partidarios de Fernando IV-y otros lugares hacia 1297 y 1298, lo que explica que en 1300 los visitadores depusieran al prior acusado de falsificación monetaria ${ }^{57}$.

En la guerra civil entre Pedro I y su hermanastro, Enrique de Trastámara, el monasterio de Sahagún apoyó al rey legítimo mientras que el concejo mantuvo una posición cambiante hasta 1366, en que se decantó por el Trastámara. Durante el tiempo que el cenobio se mostró partidario de Pedro I, además de enviarle ballesteros como señalamos en el epígrafe anterior, también contribuyó económicamente con su causa, ante la petición del monarca en 1358. Sin embargo, a partir de 1366 es posible que el abad apoyara a Enrique II como nos indican varios privilegios concedidos por el mismo al monasterio benedictino. Cabe pensar que deseara conseguir las partidas económicas necesarias para que partieran las compañías, no aumentara su deuda y pudiera pacificarse el reino y restablecerse la normalidad ${ }^{58}$.

En el siglo XV el cardenal Pedro de Frías donó al monasterio de San Jerónimo de Espeja 50.000 florines de la fortaleza de Cabrejos, cantidad que Juan II tomó "para una necesidad". Posteriormente el rey recompensó al monasterio con una renta perpetua de 1.000 maravedís anuales por cada fraile situada en Valdenebra. Según el cronista el rey se ofreció devolver la cuantía íntegra que había tomado a los jerónimos, pero finalmente, por voluntad de los religiosos, que eran veinticinco, aceptaron los 25.000 maravedís correspondientes a razón de 1.000 maravedís por cada uno de ellos ${ }^{59}$.

Otro monasterio que contribuyó económicamente a las necesidades bélicas de los monarcas del siglo XV fue San Pedro de Cardeña. El cenobio había recibido una

Reglero de la Fuente, Amigos exigentes, p. 70.

Martínez Liébana, El dominio señorial, pp. 671 y 675.

Sigüenza, Historia de la Orden, p. 181. 
cuantía de 200.000 maravedís gracias a la indulgencia conseguida por el abad Pedro del Burgo del papa Eugenio IV. Dicho montante fue entregado a Juan II quien, ante las exigencias económicas de la guerra pidió al abad que le diese el dinero con el compromiso de devolverlo. Unos años más tarde, durante el reinado de su sucesor, Enrique IV, fruto de las mismas necesidades económicas para sufragar los costes de las guerras civiles procedió igual que su padre. A través de su contador mayor, Diego Arias de Ávila, consiguió 400.000 maravedís. En virtud del dinero que el monasterio entregó a ambos monarcas, Enrique IV le otorgó un privilegio el 10 de enero de 1473, en que le concedía 40.000 maravedís anuales situados en las alcabalas de varios lugares, otras rentas y treinta excusados de tributos reales y concejiles ${ }^{60}$. Entre los motivos por los que concedió este privilegio, el monarca indicó que el abad Diego de Belorado

por me fazer servicio e porque yo pudiese ser socorrido para mis necesidades, renunciaron e traspasaron en mi todos los maravedis que al dicho monesterio eran debidos por qualesquier personas de la indulgencia que el Santo Padre Eugenio [...] dio e otorgo para el reparo e reedificacion del dicho monesterio e enmienda e equivalencia de un quento e 600.000 maravedis que el dicho rey mi señor e mi padre e yo, levamos de los maravedis de la dicha indulgencia: el dicho rey mi señor e mi padre un quento e 200.000 maravedis [...] e yo 400.000 maravedis los quales recibió por mi mandado Diego Arias de Avila mi contador mayor e del mi consejo e otros por el que son el dicho un quento e 600.000 a los quales segund el tenor de la qual bula que el dicho Santo Padre dio, somos tenudos e obligados a la restitucion e los non podemos levar sin gran cargo de nuestras consciencias ${ }^{61}$.

\subsection{Las contribuciones económicas en las guerras exteriores castellanas}

Al igual que acabamos de señalar para los conflictos internos de la Corona de Castilla, las necesidades económicas de los monarcas también obedecían a los varios frentes abiertos con otros reinos cristianos vecinos como Aragón, Navarra y Portugal, además de los musulmanes granadinos.

Por lo que respecta a la lucha contra el musulmán, durante el reinado de Sancho IV el abad Pedro de Sahagún, fue convocado por el arzobispo de Toledo al concilio que se celebró en Valladolid por orden del papa para exhortar y animar a los fieles a ir o contribuir con la guerra de Tierra Santa ${ }^{62}$. Entre febrero y marzo de 1294 el monarca fijó las cantidades con las que varios monasterios debían contribuir en concepto de "ayuda" para la campaña de Algeciras. Además del monasterio benedictino de Sahagún, el monasterio de Aguilar debía aportar 500 maravedís, San Leonardo de Alba 300 maravedís y el monasterio cisterciense de Moreruela debía entregar 2.000 maravedís ${ }^{63}$. El monasterio de San Zoilo de Carrión debía pagar 4.000 maravedís y el prior de Villafranca $500^{64}$. Las necesidades económicas del rey para la guerra contra el musulmán quedan bien reflejadas en la carta que envió el 2 de marzo de 1294 al monasterio de Valparaíso, similar a las anteriores que hemos hecho alusión:

\footnotetext{
$60 \quad$ Nieto Soria, Iglesia y génesis, p. 339.

${ }_{61}$ Berganza, Antigüedades de España, pp. 235-243.

62 Escalona, Historia del real monasterio, p. 159.

63 Gaibrois de Ballesteros, Sancho IV, no 529.

64 Reglero de la Fuente, Amigos exigentes, p. 43.
} 
bien sabedes de como este otro anno que paso fuemos a la frontera por mucha grand guerra e por mucho danno que el rey Abeyacob fazia en la nuestra tierra e como cercamos la villa de Tarifa [...] et por conplir todas aquestas cosas e otras muchas que avemos de fazer que son a servicio de Dios e a Bon paramiento de nuestros regnos, avemos mester grand aver el qual no podemos escusar como quier que nos sea muy grieve que nos roguemos e pidamos a vos y a los otros prelados de nuestros regnos que nos ayudedes con algun aver de que nos acorramos para esto que avemos a cumplir e que nos avemos de parar. Por que vos rogamos e vos mandamos que nos ayudedes con 500 maravedis [...] en guisa que lo ayamos luego este mes de março ${ }^{65}$.

Por lo que respecta a las guerras con la Corona de Aragón, en 1290 Sancho IV pedía un servicio a los eclesiásticos para tal fin. Entre los religiosos se encontraba el prior de San Román de Entrepeñas. Años después, en 1359 tenemos constancia de un nuevo pedido de 15.000 maravedís de Pedro I a Nájera con el mismo fin; el monasterio tuvo dificultades para pagarlos por lo que el prior Giraldo tuvo que empeñar al concejo de Logroño dos aldeas. Si el prior no las recuperaba en el plazo de una año quedarían para el concejo para siempre. Sin embargo el concejo no pagó dicha cantidad, lo que aprovechó el nuevo prior, Guido, para acudir al rey y solicitar una rebaja. La cantidad se redujo a la mitad a la vez que el rey demandaba al concejo de Logroño desembargar tales aldeas en $1362^{66}$. Del otro lado de la moneda, los monarcas también se encargaron de eximir a algún monasterio en particular de dichas aportaciones económicas. Esto fue lo que ocurrió con las clarisas de Guadalajara a las que Pedro I eximió a través de una provisión fechada el 7 de julio de 1361, en la que ordenaba a los repartidores del arzobispado de Toledo que no exigiesen a las monjas parte alguna en el repartimiento que el rey había pedido al arzobispo y clero de Toledo con motivo de la guerra con Aragón ${ }^{67}$.

Uno de los mecanismos empleados por Alfonso XI para superar las limitaciones fiscales y triunfar sobre sus enemigos fue la apropiación de recursos eclesiásticos, especialmente cuando se trataba de los musulmanes. Aunque los impuestos eclesiásticos se recaudaban a nivel local, los monarcas necesitaban la licencia papal antes de apropiarse de cualquier renta de este tipo. El recurso más importante era la bula de cruzada que además del reclutamiento de tropas permitía a Alfonso XI el uso de ciertas rentas eclesiásticas. En el caso de este tributo, el monarca lo consiguió en cinco ocasiones entre 1317 y 1342 . Otra renta de este tipo eran las tercias reales, equivalentes a las dos novenas partes del diezmo eclesiástico, destinadas a la construcción y conservación de los edificios religiosos. Fueron concedidas al infante Pedro en 1317 para financiar su campaña contra Granada y en varias ocasiones entre 1328 y 1349; igualmente las décimas, o el diez por ciento de todas las rentas eclesiásticas, fueron concedidas en cuatro ocasiones entre 1317 y $1343^{68}$.

Gaibrois de Ballesteros, Sancho IV, $\mathrm{n}^{\circ} 525$.

Reglero de la Fuente, Amigos exigentes, pp. 43-49.

Díaz Martín, Colección documental de Pedro I, n 1158.

68 Agrait, "El asta de la lanza", pp. 104 y 109-117. Sin embargo, un siglo después, cuando Martín V otorgaba la bula "Quoniam Maligno" (1421) por la que concedía a los monarcas de Castilla las tercias para destinarlas al conflicto musulmán, se eximió de las mismas a algunos monasterios como San Benito de Valladolid, la cartuja del Paular y los jerónimos de Montamarta, en Nieto Soria, Iglesia y génesis, pp. 319-320. 
Además del recurso a la cruzada, tercias y décimas, Alfonso XI también se sirvió del apoyo económico de los institutos regulares para la guerra a través de varios pedidos extraordinarios. En 1326 el monarca expidió una provisión estableciendo una contribución especial para todos los vecinos de Mayorga y su comarca de la que formaba parte el monasterio de Vega ${ }^{69}$. En 1338 el prior de Carrión tuvo que enviar dos caballos valorados en 1.000 maravedís además del yantar. Un nuevo servicio extraordinario fue solicitado a los clérigos y monasterios de Palencia: 400 maravedís a San Isidro de Dueñas y otros 100 maravedís a San Román de Entrepeñas ${ }^{70}$. Ante la necesidad de moneda para hacer la guerra a los musulmanes, Alfonso XI no sólo dispuso de las alcabalas, sino que también igualó en las contribuciones a las personas exentas por privilegios reales, entre las que obviamente se encontraban los institutos regulares $^{71}$. Para la toma de Algeciras, el monarca empleó el montante que rentaban las escribanías del monasterio de Sahagún para el abastecimiento del ejército. Al medio año de ser tomado dicho lugar, el 24 de septiembre de 1344 el monarca restituyó al monasterio las escribanías que había tomado y que el monasterio tenía por privilegio de su padre, el rey Fernando IV ${ }^{72}$. Una de las consecuencias de todo ello fue que desde la primera intervención benimerín del monarca en 1333 y después en el cerco de Algeciras (1343-1345), "Castiella fue despechada e en gran trebuto metida", como expresaba la queja expuesta por los prioratos cluniacenses en el capítulo general de este último año ${ }^{73}$.

En 1335, tras las campañas granadinas, Alfonso XI hizo libramientos a sus vasallos para ir a la guerra de Portugal. Sin embargo, los habitantes del reino estaban exhaustos por todos los pedidos de las continuas guerras pasadas no pudiendo recaudar el monarca tanto como pensaba. Ante esta situación, una vez más los obispos y abades del reino aportaron grandes cantidades de sus rentas ${ }^{74}$. El caso del monasterio de Cardeña fue paradigmático, como comentaremos con más detalle posteriormente, ya que se libró del pago monetario por prestar una cruz de su ajuar para la batalla. Estos hechos dieron lugar a la reacción de algunos monasterios, contrarios a dichas contribuciones, como ilustra el monasterio de San Pedro de las Dueñas: en septiembre de 1337 protestó ante el abad de San Benito de Sahagún por la asignación que había hecho a su monasterio de 800 maravedís con motivo de dicha guerra alegando su pobreza y no estar obligado a ello en virtud de los privilegios que poseía el monasterio. Ante esta situación el cenobio amenazó con recurrir al papa si el abad no cejaba en su empeño ${ }^{75}$.

En la guerra emprendida contra el reino de Portugal por Juan I de Castilla en sus aspiraciones a hacerse con la corona del mismo, los monasterios castellanos también contribuyeron económicamente con su causa. Por lo que respecta a la diócesis de Calahorra, conocemos el repartimiento de 1384, en el que los monasterios aportaron

\footnotetext{
Domínguez Sánchez, "El monasterio de Vega”, pp. 43-44.

Reglero de la Fuente, Amigos exigentes, pp. 44-45.

Berganza, Francisco de, Antigüedades de España, p. 204.

VV. AA., Colección diplomática, n 2253; González Crespo, Colección documental de Alfonso XI, $\mathrm{n}^{\circ} 301$.

Rex Castellae percipit et levat majorem partem frutuum omnium et reddituum omnium ecclesiarum sui regni, maxime benefiorum ordinis Cluniacensis, propter guerram quam habet contra sarracenos. Super hoc scriba prior claustralis Cluniacensis domno Cluniacensi ut provideat de remedio opportuno, en Senra Gabriel y Galán, "Alfonso XI y Cluny", p. 557.

74 Cerca y Rico, Cronica, p. 336; Sánchez-Arcilla Bernal, Alfonso XI, p. 180.

75 Fernández Catón, Catálogo del archivo, nº 63.
} 
diferentes cantidades ${ }^{76}$. El 2 de diciembre de dicho año el monasterio de Santa Clara de Salamanca daba carta de pago de 110 maravedís a David Abenaex, encargado de recaudar las décimas que el rey había impuesto a los essentos y monaterios del obispado de Salamanca deste anno en que agora estamos ${ }^{77}$. También conocemos un adelanto del prior de Guadalupe a Juan I para las campañas contra Portugal, cuando este templo aún no había sido entregado a la orden jerónima, sino que era un priorato seglar ${ }^{78}$. El 14 de agosto de 1385 fue derrotado en la batalla de Aljubarrota, para la que se había servido del tesoro del referido santuario ${ }^{79}$. La persistencia del rey en reclamar el trono luso continuó y el 30 de junio de 1386 el monarca vendió o, mejor dicho, obligó al santuario a comprar el portazgo y la escribanía de Trujillo y su término por 180.000 maravedíes

por los grandes menesteres en que estamos desta guerra que avemos contra los traydores rebeldes del nuestro regno de Portogal para fazer moneda e pagar sueldo asy a los nuestros naturales como a las gentes estrangeras que vienen a nos servir ${ }^{80}$.

El dinero no fue necesario tan pronto como se esperaba ya que en lugar de acciones militares el rey optó por la vía diplomática. En mayo de 1388 aún no se había efectuado el pago pero, debido a la indemnización acordada al duque de Lancaster tras las treguas de Bayona, el rey reclamó el dinero al prior quien lo entregó valiéndose, entre otros objetos preciosos, del antiguo trono de plata de la Virgen ${ }^{81}$. Las peticiones económicas a Guadalupe continuaron en el reinado de su sucesor, Enrique III, quien cuando impuso subsidios extraordinarios al clero castellano incluyó al ya monasterio jerónimo entre los cenobios que debían pagar a la archidiócesis de Toledo ${ }^{82}$.

Con la llegada del siglo XV la predicación de cruzada que se realizó en Castilla durante la minoría de edad de Juan II y la regencia de la reina-madre Catalina de Lancaster y del infante Fernando, su tío, se produjo exclusivamente en los territorios de este último. La predicación de las indulgencias que conseguirían aquellos fieles que acudieran a la cruzada contra los musulmanes o que la financiaran con limosnas de entre 240 a 5.000 maravedís, corrió a cargo de dominicos, franciscanos y cistercienses ${ }^{83}$. El franciscano fray Diego de Moxena de Valencia de Don Juan estaba en Toledo a comienzos de 1407 y probablemente tenía una bula de Benedicto XIII a favor de la cruzada contra los musulmanes que había comenzado a organizar Enrique III en los últimos meses de 1406 y que fue continuada por Fernando de

76 Toloño aportó 60 maravedís, Santa Pía 100 maravedís, el abad de San Juan de Logroño 80 maravedís, San Millán de la Cogolla 1.200 maravedís, San Prudencio de Monte Laturce 140 maravedís, Herrera 910 maravedís, Nájera 900 maravedís, Bujedo 100 maravedís, Fitero 60 maravedís y el monasterio de Cañas 130 maravedís, en Marcos Pascual, Estudio histórico-canónico, Apéndice Documental, $\mathrm{n}^{\circ} 152$.

77 Riesco Terrero, Datos para la historia, $\mathrm{n}^{\circ} 131$.

78 Beceiro Pita, "La nobleza y las órdenes mendicantes", p. 340.

79 Colmenares, Historia de la insigne ciudad de Segovia, p. 520.

80 Cerro Herranz, Documentación del monasterio, $\mathrm{n}^{\circ} 155$.

81 Sin embargo, tampoco en esta ocasión el priorato de Guadalupe entregó todo el montante debido. Enrique III envió una carta el 6 de septiembre de 1392 al ya obispo de Sigüenza y anteriormente prior de Guadalupe, comunicándole que debía pagarle a su tesorero, Rodrigo Ordóñez de Villayzan, lo que faltaba de los 1.000 marcos de plata que había prometido a Juan I a cambio del portazgo y escribanías de Trujillo. Tampoco debió pagar en esta ocasión ya que 6 meses mas tarde, el 13 de marzo de 1393 vuelve a reclamarle el pago, en Revuelta Somalo, Los jerónimos, pp. 179-180 y 188.

82 Revuelta Somalo, Los jerónimos, p. 197.

83 Echevarría Arsuaga, Catalina de Lancaster, pp. 142-143. 
Antequera ${ }^{84}$. El momento más activo tuvo lugar cuando en 1410 terminó la tregua castellano-granadina y varios dominicos prepararon a las poblaciones para la guerra, con el "discurso legitimador": en mayo de 1410, el prior de Santo Domingo de Murcia predicó la bula; el 28 de febrero de 1412, en vísperas de la conclusión de una tregua con Granada, se vuelve a recoger otra predicación semejante a cargo de fray Rodrigo de La Coruña en el castillo de las Peñas de San Pedro ante la asamblea de la ciudadela ${ }^{85}$. Sin embargo, en 1414 la ausencia de Fernando de Antequera en Castilla generó un escándalo: en la provincia que regía los frailes que recaudaban el tributo de la Cruzada se habían gastado en asuntos privados gran parte del mismo, recayendo la responsabilidad en el infante ${ }^{86}$. Esta costumbre de encomendar la predicación a los mendicantes de las bulas de Cruzada continuó, como se aprecia en 1456 ó 1457, cuando Enrique IV ordenó su predicación al franciscano observante fray Alonso de Espina $^{87}$.

A comienzos del siglo XV, el arzobispo de Sevilla Gonzalo de Mena encomendó antes de su muerte la continuación de la fábrica de la cartuja de Las Cuevas al burgalés Juan Martínez de la Victoria, canónigo de la catedral de Sevilla y su criado. Sin embargo una vez más, debido a la causa bélica el canónigo no pudo cumplir los deseos del prelado ya que se vio obligado a entregar 30.000 doblas moriscas -que el arzobispo había dejado para tal fin- al infante Fernando para la guerra de Andalucía en detrimento de la cartuja ${ }^{88}$.

En 1429, ante la petición de Juan II tuvo lugar una reunión de Consejo en Burgos con motivo de declarar la guerra a los reinos de Aragón y Navarra. El rey había pedido mucho dinero prestado a varios personajes e instituciones de Castilla y aún así, los recursos eran insuficientes. El monarca recurrió entonces a las principales iglesias y monasterios de la Corona para que contribuyeran económicamente, encargando también a algunos eclesiásticos las labores de recaudación ${ }^{89}$. Un año después, en las Cortes de Burgos, se produjo la consiguiente queja de los eclesiásticos para que no se tomase oro, plata ni piedras preciosas de las iglesias y monasterios. El rey respondió que él no había tomado nada "salvo lo que les pluguiese de me prestar para esta necesidat, con entençion de gelo tornar" $"$. Vuelve a plantearse la queja en las Cortes de Palenzuela de 1432, respondiendo el rey en esta ocasión que ordenaría a los contadores que pagasen lo debido ${ }^{91}$ y las reclamaciones volvieron a producirse en otras dos reuniones de Cortes: en las de Zamora de $1433^{92}$ y en las Madrigal de $1438^{93}$. En esta última reunión los eclesiásticos añadían en la queja que temían que los maravedís "nunca les serían pagados".

Las demandas económicas a los institutos regulares no siempre fueron fruto de la voluntad regia. Sirva como ejemplo la convocatoria de todos los príncipes y prela-

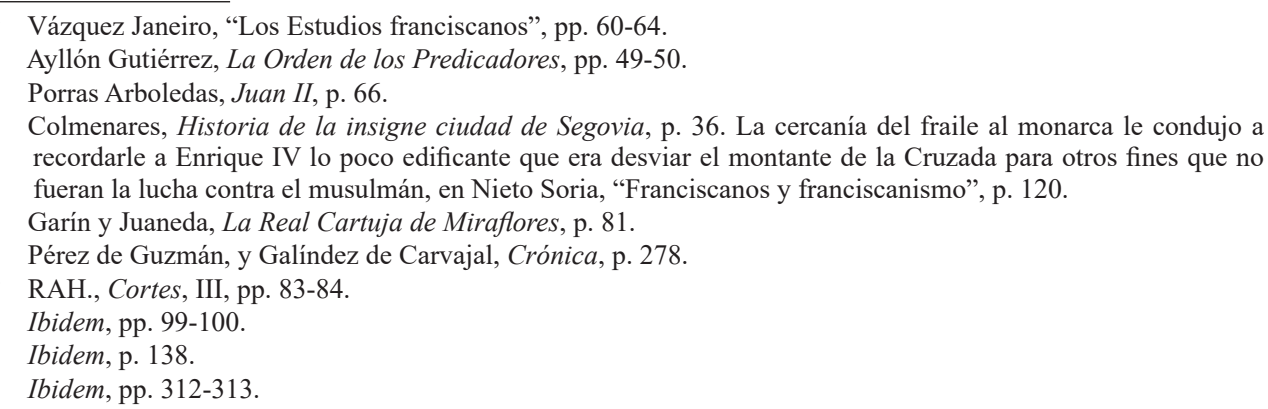


dos por el papa Calixto III en 1457, ante la entrada de los turcos en Occidente ordenando que se repartiesen ciertas sumas de dinero por sus reinos, correspondiéndole a Castilla 100.000 florines de oro del cuño de Aragón a repartir entre los diferentes obispados. Se produjeron quejas por parte los exentos, siéndonos conocido el caso del obispado de Segovia, donde su titular nombró al prior del Parral, fray Pedro de Mesa, al prior de Santa Cruz y al comendador de San Antolín para que, junto a un cura y un maestrescuela, dilucidasen la verdad acerca de los exentos y se la comunicasen ${ }^{94}$.

Si importante fue la labor política y arbitral de la clerecía regular en las turbulencias políticas y guerras de los dos últimos siglos de la Edad Media en Castilla, no menos lo fueron las diferentes contribuciones económicas que los diversos cenobios aportaron para sufragar las luchas internas y guerras externas de la Corona. En este caso, fueron las órdenes benedictina, cluniacense y cisterciense quienes de forma exclusiva aportaron los fondos, cuestión muy relacionada con las extensas posesiones, rentas y censos que poseían las mismas. La participación de los mendicantes en asuntos económicos concernientes a la guerra también fue destacada, no aportando caudales, sino exhortando e incentivando con sus predicaciones a las distintas poblaciones a hacerlo.

\section{El papel de los monasterios como intercesores en la batalla}

Además de las labores políticas y económicas que hemos comentado anteriormente, los cenobios y sus comunidades jugaron otro papel de carácter menos material, pero sin duda igual de necesario a la hora de emprender las campañas militares. Algunos reyes e infantes se sirvieron de la presencia de algunos religiosos de su confianza y de algunos objetos del ajuar litúrgico de ciertos monasterios por la importancia de su carácter intercesor para lograr la victoria contra el enemigo. En otros casos también solicitaron las devotas oraciones de algún cenobio con el mismo fin.

En el pedido monetario que hizo Alfonso XI a los monasterios para su guerra contra Portugal un caso paradigmático que anunciamos anteriormente fue el del monasterio de Cardeña. El rey lo eximió del pago que le correspondía para la guerra de 3.000 maravedís a cambio de que su abad, por segunda vez -la primera había tenido lugar durante el cerco de Gibraltar de 1333-, le prestase la Cruz de las Batallas, que según la tradición había pertenecido al Cid. La petición del monarca data del 8 de marzo de 1337, en la cual se dirigió al abad con estas palabras

por gran deboçion, que habemos en la cruz de y del monesterio la qual lleuamos la otrauez quando fuimos sobre Gibraltar, tenemos por bien de ynbiar por ella para la leuar connusco en esta yda que ymos a Portugal. Enbiamos halla para que nos trayan Aluar Roiz e Juan Garçia, nuestros vallesteros, e vos que enbiedes dos monjes con ella que nos la trayan. (...) e sed çiertos que desque nos Dios traya de alla luego la ynbiaremos y al dicho monesterio asi como la feçimos la otra vegada [...] Otrosi bien sabedes en como todos los perlados e las hordenes de nuestro señorio nos siruen en cada uno dellos con quitanças çiertas de maravedis para estas guerras, que hauemos e hauiamos ordenado que vos el dicho abad e convento nos

94 AHN, Clero, Pergaminos, Carp. 1.969, № 14. 
siruiesedes con tres mil maravedis. E por la deuoçion que hauemos en ese lugar e en la dicha cruz tenemos por bien de vos las quitar e que las non paguedes ${ }^{95}$.

Tenemos constancia de la asistencia del confesor de Alfonso XI, fray Juan de Entrega, en la batalla del Salado, seguramente prestando servicios religiosos al monarca e infundiéndole el ánimo necesario para las mismas ${ }^{96}$. Como señala Miura Andrades, los religiosos acompañaban a los ejércitos como capellanes de los reyes, de los nobles o de la tropa. En la conquista de Niebla los mismos jugaron un importante papel: sus sitiadores se vieron amenazados por una plaga de moscas ante lo que dos religiosos dominicos, fray Andrés y fray Pedro, tuvieron la idea de ofrecer dos torneses de plata por almud de moscas, gracias a lo cual desapareció la plaga ${ }^{97}$.

En otros casos los monarcas acudieron a algunos de los monasterios más antiguos y famosos de Castilla, solicitando sus oraciones para que las campañas tuvieran el fin esperado. Así ocurrió en el transcurso de la guerra civil entre Pedro I y Enrique de Trastámara, cuando el 27 de enero de 1367 este último envió una carta a los monjes de Cardeña pidiéndoles que rogaran a Dios para obtener la victoria sobre sus enemigos $^{98}$.

El infante Fernando también se sirvió de la labor intercesora de los religiosos y del ajuar de algunos monasterios en sus campañas andaluzas. En 1406, cuando se enteró que los musulmanes estaban en Cañete fue a Sevilla acompañado de varios nobles del reino, llegando a la puerta de San Agustín donde le esperaban los frailes con una cruz sobre un paño; el infante descendió del caballo, rezó y la besó ${ }^{99}$. Antes de partir a Antequera, Fernando se dirigió al monasterio jerónimo de la Mejorada para encomendarse a Dios, en las oraciones de sus frailes y para pedir consejo a su confesor, el prior fray Juan de Nava, a quien llevó consigo como padre espiritual, confiando que su compañía le llevaría a la victoria. Llevó también un crucifijo pequeño que estaba en una capilla de la iglesia conventual al que "tenía mucha devoción, donde se estaba muchos ratos de rodillas"; el 24 de septiembre de 1410, tras su conquista, el regente entró en Antequera precedido de fray Juan de Nava con el crucifico en las manos y después regresaron a la Mejorada y mandó ponerlo encima de la reja de la capilla mayor ${ }^{100}$. El prior de Guadalupe y confesor del infante Fernando, fray Alfonso de Pastrana, también le acompañó en dicha campaña llevando consigo un crucifijo del monasterio; en la toma de la ciudad obtuvo del infante el privilegio de entrar en ella portando el crucifijo y el pendón del regente, que tenía una imagen de la Virgen a la que bendecía Dios Padre. Posteriormente con el pendón se hizo un frontal de altar para el monasterio ${ }^{101}$. Para dicha campaña, el infante también envió que fueran a buscar el pendón de San Isidoro de León, como era costumbre de los reyes de Castilla llevarlo consigo cuando entraban en guerra con los musulmanes. El 10 de septiembre, un monje acompañado de gente armada se lo llevó al Real. Finalmente, el 1 de octubre Fernando ordenó bendecir la mezquita que estaba en el castillo de Antequera; para ello fue en procesión desde su real con todos los clérigos

\footnotetext{
Cañas Gálvez, Itinerario de Alfonso XI, pp. 102 y 116-117.

VV. AA., Diccionario, p. 600.

Miura Andrades, Frailes, monjas y conventos, pp. 150-151.

Valdeón Baruque, Enrique II, p. 80.

Pérez de Guzmán y Galíndez de Carvajal, Crónica, p. 56.

Sigüenza, Historia de la Orden, p. 294.

101 Revuelta Somalo, Los jerónimos, p. 224.
} 
y frailes que portaban las cruces y reliquias de su capilla y los pendones de la Cruzada, Santiago, San Isidro de León y los de sus armas y divisas ${ }^{102}$.

En el Real de Almajano, el 27 de julio de 1430 Juan II se reunió en su tienda con su Consejo. Ambas partes oyeron misa que fue oficiada por su confesor el obispo dominico de León, fray Alfonso ${ }^{103}$. Un año después, el 20 de julio de 1431, Juan II desde el Real de Granada se dirigió a Córdoba donde fue recibido con solemnidad por sus victorias por el obispo y toda la clerecía secular y regular "hasta la puente de la cibdad", dando gracias a Dios por la victoria contra el infiel ${ }^{104}$.

Como acabamos de observar, en la mentalidad de la época, el continuo recurso por parte de los monarcas e infantes a la labor intercesora de algunos frailes, a los pendones o ajuar litúrgico de los monasterios o las oraciones que en ellos se llevaban a cabo para el buen término de las batallas, reflejan la importancia de la misma. El papel intercesor estuvo a la misma altura que la labor política del clero regular y sus aportaciones económicas.

\section{Las infraestructuras monásticas: refugios, bastiones y firma de acuerdos}

\subsection{Lugares de residencia provisional y asilo}

Las infraestructuras monásticas fueron empleadas en medio de las contiendas como lugares donde asentar el real o albergue provisional por los diferentes bandos en litigio. En unos casos lo hicieron como simple hospedaje para proseguir la marcha en pocos días; otras veces, se sirvieron de la sacralidad y consistencia de sus muros para refugiarse tras los mismos en momentos tensos. Sin embargo, no en todas las ocasiones se respetó el espacio sagrado produciéndose asaltos violentos a los monasterios, contando incluso con algún ejemplo de homicidio dentro de las iglesias conventuales.

Los conflictos continuaron ante la inesperada muerte de Fernando IV y el ascenso al trono de su heredero, Alfonso XI, cuando contaba apenas con un año de edad. En medio de las tensiones surgidas en 1313 entre el infante Pedro, por una parte y los infantes Juan y Felipe de la otra, varios monasterios fueron empleados como residencia provisional. El infante Juan huyó al monasterio San Pedro de Dueñas y cerca de Sahagún el infante Pedro se reunió con el infante Felipe y le reprochó que hubiera tomado el partido de sus adversarios. Este se alojó tres días en el convento de San Francisco y sus contrarios permanecieron en monasterio de Dueñas, sin atreverse a salir. Ante esta situación, Juan Núñez de Lara se dirigió a Cuéllar para reunir a los representantes de las ciudades de Extremadura y suscribió una carta de hermandad con los concejos de León, Zamora, Astorga, Mansilla y Benavente. Cuando el infante Pedro conoció estos hechos fue a Olmedo con la intención de atacar Cuéllar donde escogió de nuevo como alojamiento el convento de San Francisco, permaneciendo allí cuatro días ${ }^{105}$. La situación de Alfonso XI se hacía cada vez mas difícil ante la sublevación de don Juan Manuel ${ }^{106}$. Ante esto el monarca decidió enviar contra él a

102 Pérez de Guzmán y Galíndez de Carvajal, Crónica, pp. 90-98; Nieto Soria, Iglesia y génesis, p. 235.

103 Cañas Gálvez, El itinerario de la corte de Juan II, p. 67.

104 Pérez de Guzmán y Galíndez de Carvajal, Crónica, p. 322.

105 Sánchez-Arcilla Bernal, Alfonso XI, p. 46; Cerca y Rico, Cronica, pp. 15-16.

106 Sánchez-Arcilla Bernal, Alfonso XI, p. 128. 
Alvar Núñez y a Garci Laso de la Vega, para que reclutasen algunos hombres de Soria y fuesen contra don Juan Manuel. Cuando Garci Laso llegó a Soria, los habitantes se enteraron de que iba a tomar caballeros de la ciudad y reaccionaron asesinando al noble mientras oía misa en el convento de San Francisco ${ }^{107}$.

Al igual que en el caso de los hombres, ciertas mujeres de la nobleza o de la familia real también emplearon los muros monásticos para refugiarse, en este caso en comunidades religiosas femeninas. Es probable que María y Aldonza Coronel se refugiaran en Santa Clara de Sevilla cuando sus respectivos maridos, Juan de la Cerda y Alvar Pérez de Guzmán respectivamente, se sublevaron para entregar Andalucía al rey aragonés en 1358. Aldonza debió de salir de los muros monásticos, Pedro I la prendió y terminó encerrada en la Torre del Oro ${ }^{108}$. En el monasterio de Santa Clara de Tordesillas fue recluida la infanta Catalina, hermana de Juan II durante el secuestro del rey por parte del infante Juan para era evitar casarse con el infante Enrique ${ }^{109}$. El rey envió a varios personajes para sacarla del monasterio, lo cual se consiguió cuando el obispo de Palencia amenazó que procedería contra la abadesa y que Garci Fernández Manrique, I conde de Castañeda, haría demoler el monasterio. Tras ello permitieron a Juan II pasar a la cámara de la reina su prima y cuñada haciéndola antes la promesa de que ni le apartaría de su aya Mari Barba, ni le obligaría a casarse con el infante ${ }^{110}$.

En otros casos, los monasterios prestaron asistencia a las tropas de otros reinos. En 1437 el infante Fernando de Portugal, hermano del rey Duarte fue a la conquista de Tánger. La ciudad recibió apoyo por parte de otros musulmanes norteafricanos y los portugueses fueron vencidos quedando como rehén el confesor del infante. Al regreso de su derrota pasaron por Guadalupe donde el prior, ante el estado en que se encontraban los lusos, mandó que les proveyesen de lo necesario, incluido dinero para su regreso ${ }^{111}$.

En 1441, por consejo de Juan Pacheco, el príncipe Enrique se refugió en Segovia para negociar con el rey de Navarra. El 25 de febrero se concertó una entrevista en Santa María de Nieva entre el príncipe y el marqués de Villena con las reinas de Castilla y Navarra. Infructuosamente esperaron durante dos días que Juan II se acercase a Arévalo. Los rebeldes culparon de este fracaso al condestable y varios nobles partieron desde Arévalo para luchar contra Álvaro de Luna, quien se sirvió del arzobispo Juan de Cerezuela, su hermano, para reforzar sus tropas. Ambos hermanos se instalaron durante dos horas en el monasterio de San Agustín de Casarrubios, esperando la llegada del adversario; al no aparecer el rival, el día siguiente hicieron lo propio en la ermita de Santa María de Batres, obteniendo el mismo resultado, ante lo que Álvaro de Luna se fue a Maqueda y el arzobispo a Illescas ${ }^{112}$. El rey de Navarra pidió a Juan II que le dejara entrar en Medina del Campo pues venían en su servicio contra el condestable, ante lo que el monarca, en mayo de dicho año les ordenó que disolviesen su ejército como condición para permitirles entrar. El mismo día Juan de

\footnotetext{
107 AHN, Clero, Códices, L. 1264, f. 5.

108 Sitges, Las mujeres del rey, pp. 415-420; Rodríguez Liañez, "El archivo de Santa Inés de Sevilla”, pp. 126-127; López de Ayala, Crónicas, pp. 184-185.

109 Castro y Castro, El Real Monasterio, p. 65.

110 Salazar y Castro, Historia genealógica, I, p. 493; Porras Arboledas, Juan II, p. 95; Rodríguez Guillén, El monasterio, p. 70.

111 Sigüenza, Historia de la Orden, p. 489.

112 Porras Arboledas, Juan II, pp. 220-221; Pérez de guzmán y Galíndez de Carvajal, Crónica, p. 422.
} 
Navarra consiguió volver a Olmedo y expulsar a las tropas realistas. La reina y el príncipe dejaron Arévalo y fueron al monasterio de La Mejorada. E1 2 de junio todos los rebeldes acudieron a poner su real sobre Medina del Campo, donde Juan II ordenó a sus tropas junto al monasterio Santa Clara. La reina y el príncipe se aposentaron en Santa María de Dueñas, donde tuvo lugar un infructuoso intento de concordia el 6 de junio de $1441^{113}$.

Por tanto, en el seno de las contiendas bélicas los numerosos monasterios repartidos a lo largo y ancho de la geografía castellana fueron empleados en algunas ocasiones como lugares de refugio provisional y en otras como lugares de reclusión o presidio; en ambos casos se aprecia la importancia desempeñada por los cenobios en los diferentes episodios de violencia en la Castilla bajomedieval.

\subsection{La celebración de cortes, treguas y acuerdos de paz}

En medio de las contiendas en las que se vio inmersa Castilla en la Baja Edad Media, los edificios monásticos y conventuales fueron escenario de algunas reuniones de Cortes en momentos tensos y allí se debatieron algunos asuntos concernientes a la guerra. Sin embargo, el mayor número de ejemplos de los que disponemos, hacen referencia a diversos monasterios como lugares se negociaron concordias y tratados de paz entre las partes enfrentadas.

Durante la minoría de edad de Alfonso XI el reino se encontraba dividido. Mientras Castilla, León, Galicia y Asturias eran favorables a la causa del infante Juan, Andalucía y Toledo apoyaban al infante Enrique. Esta división se puso de manifiesto en las Cortes paralelas reunidas en Palencia durante el mes de abril de 1313: los partidarios del infante Juan se reunieron en el convento dominico de San Pablo y los del infante Pedro lo hicieron en el de San Francisco, pese al intento de Rodrigo, arzobispo de Santiago, para que se convocara una única asamblea. Los procuradores de Castilla, León, Galicia y Asturias eligieron al infante Juan como tutor del rey, mientras que Toledo y Andalucía hicieron lo propio con el infante Pedro y su madre María de Molina ${ }^{114}$.

En otros casos, en los monasterios se tomaron decisiones relacionadas con la guerra. En 1342 Alfonso XI mandó que los prelados, ricos hombres, caballeros e hidalgos castellanos fuesen al convento de San Pablo de Burgos. Allí les informó de sus intenciones de regresar a la guerra contra el musulmán para conquistar Algeciras y les pidió que le otorgasen el pecho del alcabala, comprometiéndose aquéllos a darle respuesta cuando lo acordasen ${ }^{115}$.

Los recintos monásticos también fueron empleados para la firma de acuerdos de paz. E1 12 de marzo de 1375 se firmó la paz entre Castilla y Aragón en el convento de San Francisco de Almazán donde se proyectó el matrimonio entre el infante Juan y Leonor de Aragón, la devolución a Castilla de Molina y Requena, además de la entrega de dinero a Aragón por parte de Enrique II ${ }^{116}$. En 1451 se firmó el tratado de paz en Santa Clara de Tordesillas, donde el rey, el príncipe y sus partidarios fueron a oír misa junto a varios de los principales nobles del reino, quienes, después del momento

\footnotetext{
13 Porras Arboledas, Juan II, pp. 224-225.

114 Sánchez-Arcilla Bernal, Alfonso XI, p. 48; Cerca y Rico, Cronica, pp. 18-19.

115 Cerca y Rico, Cronica, pp. 473-474.

116 Valdeón Baruque, Enrique II, p. 151.
} 
de la consagración hicieron juramento público de que el príncipe Enrique guardaría servicio a su padre y Juan II de acatarlo como hijo; además, los nobles juraron servicio y lealtad al rey ${ }^{117}$. El 13 antes de septiembre de 1467 se acordó en la posada del conde de Luna que el rey Alfonso saliese al encuentro de Enrique IV para combatir. Al amanecer, la caballería salió de Olmedo con el rey y el arzobispo de Toledo y pronto llegó el enemigo. El rey Alfonso, se situó en la puerta de la ermita de Santo Domingo cerca de Olmedo junto a otros hombres. Unos días después el conde de Alba fue de Arévalo a Segovia, pasando por Santa María la Real de Nieva; después el obispo de León, Antonio Iacopo di Vernier llegó a Coca donde se ofreció hacer de mediador, por lo que se presentó el 26 de septiembre en El Parral, participando en los acuerdos que tuvieron lugar en el monasterio jerónimo ${ }^{118}$.

El último de los casos señalados, resulta particularmente curioso. En la ocupación de Carrión por parte del conde de Benavente, a la que el rey y Álvaro de Luna se mostraron favorables Pedro Manrique acudió a las armas, apoyado por sus tíos los condes de Castañeda y Osorno. Lo interesante, es que los Mendoza también se sumaron a la causa porque el marqués de Santillana, Diego Hurtado de Mendoza, tenía a sus antecesores sepultados en el convento de San Francisco de Carrión y pidió al conde de Benavente la dejase libre. Sin embargo el conde, para eliminar el pretexto del marqués le dijo que recogería los huesos de sus abuelos y se los enviaría en una espuerta para que los pusiese con los de los otros miembros del linaje en San Francisco de Guadalajara. Finalmente, el 28 de marzo de 1474, el conde de Benavente hizo pleito homenaje en el monasterio de San Zoilo en manos del conde de Castañeda su tío, prometiendo dejar la villa libre ${ }^{119}$. En este caso, además de sellarse la paz en un monasterio, también se emplearon los restos de los sepultados en otro cenobio.

\subsection{Los edificios monásticos y las infraestructura castrenses}

Además del empleo de los edificios conventuales como asilo provisional, refugio en medio de situaciones tensas y para la firma de acuerdos y tratados que pusieran fin a las mismas, también fueron utilizados para la construcción de infraestructuras bélicas en medio de los combates, principalmente bastidas.

En la toma de Calatayud de 1362 llevada a cabo por Pedro I, el monarca se sirvió de varios cenobios para la construcción de bastidas ${ }^{120}$. El rey había llegado a la ciudad con gente armada

ca les avían derribado los engeños del monesterio de Sant Francisco, e allí les avía fecho una bastida muy fuerte: otrosí les avía fecho otra bastida de partes del monesterio de San Pedro Mártir, fasta el monesterio de Sancta Clara, e tenían los muros de aquella parte unas quarenta brazas en cuentos, en manera que los del Real de fuera veían por de yuso de los cuentos e del muro a los que andaban por la villa e que no podían defenderse ${ }^{121}$.

117 Carriazo, Crónica de don Álvaro de Luna, pp. 266-267.

118 Palencia, Gesta Hispaniensia, pp. 421-423.

119 Salazar y Castro, Historia genealógica, II, pp. 120-123.

120 López de Ayala, Crónicas, p. 284.

121 López de Ayala, Crónicas, p. 284; Díaz Martín, Pedro I, pp. 200-201. 
De forma similar actuó Enrique II, quien a finales de 1367 inició una ofensiva contra los partidarios de Pedro I en el valle del Duero. El adelantado mayor de Castilla, Rodrigo Rodríguez de Torquemada, se había hecho fuerte en el castillo de Dueñas, que Enrique sitió, forzando su entrega. Durante el asedio las tropas enriqueñas se aposentaron en San Isidro de Dueñas, quemándose su claustro y parte de su iglesia ${ }^{122}$. Una años después, Enrique II tomó la ciudad de León, partidaria su hermanastro, sirviéndose para ello de los edificios del convento dominico:

E llegó allá e cercó la cibdad e fízola una bastida en el monesterio de los Predicadores, que dicen Santo Domingo, que estaba muy allegado a una torre de la cibdad, en guisa que los de la torre non podían defenderla (tan apoderados estaban los de la bastida que ficieron en el monesterio), ovieron de pleitear con el rey don Enrique, en guisa que le dieron la cibdad de León, e fincaron en la su merced los que estaban dentro en ella ${ }^{123}$.

En 1413 las tropas de Juan II cercaron Balaguer en ayuda de su tío, el rey Fernando I de Aragón, en el seno de los enfrentamientos entre este último y Jaime de Urgel ${ }^{124}$. Cerca del alcázar se encontraba un "monesterio de dueñas muy notable" donde la ciudad asentó a unos seiscientos hombres de armas de su tropa. El 25 de agosto el duque de Gandía con sus huestes entró armado en el monasterio para arrebatárselo a los vecinos de Balaguer, falleciendo algunos y siendo heridos otros. $\mathrm{La}$ crónica también nos narra como el rey aragonés no dudó en construir bastidas en el convento y tras tomar la ciudad "dexó todas las cosas de su real a los frayles de San Francisco de Balaguer, para ayudar a rehacer su monesterio que estaba derribado" 125 .

Desde Burgos, Juan II decidió marchar en persona contra Palenzuela, donde los vasallos del almirante y de su cuñado, Juan de Tovar, se oponían al monarca. El condestable y el rey asentaron a sus hombres en el convento de San Francisco -situado fuera de la villa, al otro lado del río- para comenzar desde allí la ofensiva contra los rebeldes; Álvaro de Luna ordenó construir desde el cenobio un puente de madera para acceder a la villa y tras algunas escaramuzas con los rebeldes en el convento, el condestable y su camarero, Gonzalo Chacón, cruzaron el río y negociaron con Juan de Tovar la rendición de la villa que tuvo lugar el 15 de enero de $1452^{126}$.

Por lo tanto, los distintos poderes y, en especial la monarquía, no dudaron en emplear las infraestructuras monásticas para combatir al enemigo, pese a las desastrosas consecuencias que estas acciones tenían para los institutos religiosos. Si en unos casos se produjeron daños materiales, en otros tuvo lugar la completa destrucción del cenobio.

\section{Conclusiones}

Lejos de ser algo esporádico y extraordinario, hemos podido observar como la participación de los monasterios castellanos y sus comunidades en los conflictos internos

Díaz Martín, Pedro I, p. 258.

123 López de Ayala, Crónicas, p. 405.

124 González Sánchez, "La participación de los eclesiásticos", pp. 275-276.

125 Pérez de Guzmán y Galíndez de Carvajal, Crónica, pp. 124-131.

126 Porras Arboledas, Juan II, pp. 284-285; Carriazo, Crónica de don Álvaro de Luna, pp. 271-276. 
y guerras externas en Castilla fue reiterada y frecuente durante los dos últimos siglos medievales. La colaboración de la clerecía regular se hizo a través de diferentes vías.

Los monasterios y sus comunidades desempeñaron un papel sociopolítico de primer orden en dichos conflictos siendo parte activa de los mismos. En primer lugar, tomando partido por una de las partes en litigio bien con la formación de Hermandades, bien prestando su apoyo a uno de los bandos en litigio o exhortando a las masas con sus predicaciones para generar un estado de opinión. Los distintos contendientes tampoco dudaron en recurrir a los religiosos para la participación directa en las campañas militares o en la defensa de villas y ciudades. Fue tal el recurso a la clerecía regular por parte de los monarcas que la cuestión llegó a tratarse y regularse en reuniones de Cortes como muestra el proceder de Juan I en las celebradas en la ciudad de Valladolid en 1385. En segundo lugar, la labor política de los religiosos se llevó a cabo desde una posición neutral en dichos conflictos, desempeñando la función de árbitros en los mismos, tratando de pacificar los distintos brotes de violencia.

Si importante fue la labor política del clero regular en la casus belli, no fue menor su contribución económica a la misma. Los reyes pidieron numerosas contribuciones extraordinarias a los institutos religiosos para poder financiar sus campañas militares. También hemos observado algún caso en los que los religiosos llegaron incluso a hacer uso de la falsificación monetaria para mostrar su apoyo a una de las parcialidades. Si importantes y generalizadas fueron las contribuciones económicas que entregaron los cenobios a la Corona, igual de siginificativa fue la labor de los frailes para exhortar a las masas a contribuir a las mismas a través de la promesas de salvación, como en el caso de algunas indulgencias. Igualmente, la monarquía se sirvió del poder de palabra que tenían los mendicantes para la predicación de las bulas de Cruzada e, incluso, la confianza depositada en los mismos hizo que en ocasiones se encargaran de recaudar algunos de los tributos extraordinarios demandados.

Además del componente humano de los monasterios y conventos, sus edificios e infraestructuras también fueron empleados en numerosas ocasiones como lugar de hospedaje provisional, refugio, celebración de compromisos y acuerdos de paz. Pero los poderes laicos y, en particular los monarcas, tampoco dudaron en servirse de sus recias obras para la construcción de infraestructuras castrenses, tales como bastidas, con los consiguientes daños y destrucciones de los monasterios, como ocurrió en muchos casos.

Finalmente, un último aspecto destacable de la contribución del clero regular en los aspectos militares castellanos de la Baja Edad Media, no tuvo un carácter tan marcadamente material como los anteriores: la labor intercesora. Numerosos religiosos acompañaron a los monarcas e infantes en sus campañas además de para la cura de sus almas, para infundirle los ánimos y el valor necesarios para emprenderlas. También se sirvieron de algunos objetos litúrgicos albergados en los monasterios tales como estandartes o cruces, que por su santidad y por la confianza que los monarcas depositaban en los mismos, les ayudaba a conseguir la tan ansiada victoria. Tampoco dudaron en pedir a algunos cenobios que intercedieran directamente en sus ruegos y oraciones ante Dios, para que la divinidad les ayudase a salir victoriosos.

Por tanto, la clerecía regular castellana, lejos de mantenerse al margen de los conflictos acontecidos en la Corona, participó de una forma activa en los mismos. El apoyo o la oposición a uno de los bandos en litigio, condicionó de manera obvia los privilegios y donaciones concedidos a los distintos monasterios y órdenes en función de la postura empleada, pudiéndose encontrar la explicación de los múltiples cam- 
bios que tuvieron lugar en las devociones y en las relaciones entre los poderes laicos y la clerecía regular durante el periodo bajomedieval castellano.

\section{Bibliografía}

Agrait, Nicolás, "El asta de la lanza: los mecanismos de financiación de la guerra durante el reinado de Alfonso XI (1312-1350)”, Gladius, XXXII (2012), pp. 103 120.

Álvarez Rodríguez, Alicia, Conventos y sociedad urbana durante la Baja Edad Media. La Orden de los Predicadores en Zamora, Toro y Benavente (Tesis Doctoral Inédita), Salamanca: Universidad de Salamanca, 2015.

Ayllón Gutiérrez, Carlos, Iglesia rural y sociedad en la Edad Media (Alcaraz y señorío de Villena), Madrid: Sílex, 2015.

Ayllón Gutiérrez, Carlos, La Orden de los Predicadores en el sureste de Castilla (las fundaciones medievales de Murcia, Chinchilla y Alcaraz hasta el Concilio de Trento, Albacete: Instituto de Estudios Albacetenses “don Juan Manuel” de la Excma. Diputación de Albacete, 2003.

Beceiro Pita, Isabel, "La nobleza y las órdenes mendicantes en Castilla (1350-1530)", en Isabel Beceiro Pita (dir.), Poder, piedad y devoción. Castilla y su entorno. Siglos XII-XV, Madrid: Sílex, 2014, pp. 319-358.

Berganza, Francisco de, Antigüedades de España propugnadas en las noticias de sus reyes, en la Crónica del Real Monasterio de San Pedro de Cardeña, en Historias, cronicones, y otros instrumentos manuscritos, que hasta aora no han visto la luz pública, Madrid: Francisco del Hierro, 1721.

Cantera Montenegro, Santiago, "Las relaciones de las cartujas de la Provincia de Castilla con la monarquía: 1390-1598”, en Concepció Bauçà de Mirabó Gralla (coord.), Prínceps i reis. Promotors de l'orde Cartoixà, Palma: Universitat de les Illes Balears, 2003, pp. 277-292.

Cañas Gálvez, Francisco de Paula, Colección diplomática de Santo Domingo el Real de Toledo. Documentos Reales I (1249-1473), Madrid: Sílex, 2010.

Cañas Gálvez, Francisco de Paula, El itinerario de la corte de Juan II de Castilla (1418-1454), Madrid: Sílex, 2007.

- Itinerario de Alfonso XI de Castilla. Espacio, poder y corte (1325-1350), Madrid: La Ergástula, 2014.

Carriazo, Juan de Mata, Crónica de don Álvaro de Luna condestable de Castilla maestre de Santiago, Madrid: Espasa-Calpe, 1940.

Castro Toledo, Jonás, Colección diplomática de Tordesillas, Valladolid: Institución Cultural Simancas, 1981.

Castro y Castro, Manuel de, Crónica de la Provincia franciscana de Santiago (12141614), Madrid: Archivo Ibero-Americano, 1971.

- El Real Monasterio de Santa Clara de Palencia y los Enríquez, Almirantes de Castilla, Palencia: Diputación Provincial de Palencia, 1982.

Cerca y Rico, Francisco, Crónica de D. Alfonso el Onceno de este nombre, de los reyes que reynaron en Castilla y en León, Madrid: Imprenta de d. Antonio de Sancha, 1787. 
Cerro Herranz, María Filomena, Documentación del monasterio de Guadalupe. Siglo XIV, Badajoz: Diputación Provincial de Badajoz, 1987.

Colmenares, Diego de, Historia de la insigne ciudad de Segovia y compendio de las historias de Castilla, Segovia: Academia de historia y arte de San Quirce, 1982.

Cruz, Valentín de la, La abadía cisterciense de Bujedo de Juarros (ss. XII-XIX), Palencia: La Olmeda, 1990.

Díaz Ibáñez, Jorge, "Iglesia, nobleza y oligarquías urbanas”, en José Manuel Nieto Soria (dir.), La monarquía como conflicto en la Corona castellano-leonesa (c. 1230-1504), Madrid: Sílex, 2006, pp. 197-252.

Díaz Martín, Luis Vicente, Colección documental de Pedro I de Castilla (13501369), Valladolid: Junta de Castilla y León, 1997.

Díaz Martín, Luis Vicente, Pedro I el Cruel (1350-1369), Gijón: ediciones Trea, 1995.

Díaz y Díaz, Luis Alfredo, "Alonso de Oropesa y su obra”, Studia Hieronymiana, Madrid, 1973.

Domínguez Sánchez, Santiago, "El monasterio de Vega: de los orígenes altomedievales a la Edad Moderna", en María Isabel Viforcos y María Dolores SánchezBordona (coords.), Fundadores, fundaciones y espacios de vida conventual. Nuevas aportaciones al monacato femenino, León: Universidad de León, 2005, pp. 17-50.

Echevarría Arsuaga, Ana, Catalina de Lancaster, reina regente de Castilla (13721418), Hondarribia: Nerea, 2002.

Escalona, Romualdo, Historia del real monasterio de Sahagún, Madrid: Joachin Ibarra, 1782.

Fernández Catón, José María, Catálogo del archivo del monasterio de San Pedro de las Dueñas, León: Centro de Estudios e Investigación San Isidoro, 1977.

Fernández Martín, Luis, "La participación de los monasterios en la 'Hermandad' de los reinos de Castilla, León y Galicia (1282-1284)", Hispania Sacra, XXV (1972), pp. 5-35.

Gaibrois de Ballesteros, Mercedes, Sancho IV de Castilla, Tomo III, Madrid: Real Academia de la Historia, 1928.

Galíndez de Carvajal, Lorenzo, Crónica del señor rey don Juan Segundo, Valencia: Imprenta de Benito Monfort, 1779.

García Oro, José, Francisco de Asís en la España Medieval, Santiago de Compostela: CSIC-Liceo Franciscano, 1988.

Garín y Juaneda, Francisco, La Real Cartuja de Miraflores (Burgos). Su historia y descripción, Burgos: Hijos de Santiago Rodríguez, 1897.

González Crespo, Esther, Colección documental de Alfonso XI. Diplomas reales conservados en el Archivo Histórico Nacional. Sección de Clero. Pergaminos, Madrid: Universidad Complutense de Madrid, 1985.

- Elevación de un linaje nobiliario castellano en la Baja Edad Media: los Velasco (Tesis Doctoral), Madrid: Universidad Complutense de Madrid, 1981.

González Sánchez, Santiago, "La participación de eclesiásticos castellanos en las empresas bélicas de la regencia y del reinado de Fernando I de Aragón”, Espacio, Tiempo y Forma. Serie III. H ${ }^{a}$ Medieval, 27 (2014), pp. 269-304.

Layna Serrano, Francisco, Historia de Guadalajara y sus Mendozas en los siglos XV y XVI, Madrid: CSIC, 1942. 
Linehan, Paul, La Iglesia española y el papado en el siglo XIII, Salamanca: Universidad Pontificia, 1975.

López de Ayala, Pedro, en José Luis Martín (ed.), Crónicas, Barcelona: Planeta, 1991. López, Juan, Tercera parte de la historia general de Sancto Domingo y de su Orden de Predicadores, Valladolid: Francisco Fernández de Córdova, 1613, 2 libros.

Manso Porto, Carmen, "El obispo fray Pedro López de Aguiar, O.P. (1349-1390): reseña biográfica y aproximación a los principales acontecimientos en su diócesis durante el reinado de Pedro I", Archivo Dominicano, n XIV (1993), pp. 43-68.

Marcos Pascual, Enrique, Estudio histórico-canónico de la jurisdicción eclesiástica "nullius diocesis de las Ilmas. Abadesas del monasterio de Cañas, (Tesis Doctoral Inédita), Madrid: UNED, 2015.

Martínez Casado, Ángel, Lope de Barrientos, un intelectual de la Corte de Juan II, Salamanca: Ed. San Esteban, 1994.

Martínez Liébana, Evelio, El dominio señorial del monasterio de San Benito de Sahagún en la Baja Edad Media (siglos XIII-XV), Madrid: Universidad Complutense de Madrid, 1990.

Martínez Medina y Martín Biersack, Francisco Javier, Fray Hernando de Talavera, primer arzobispo de Granada. Hombre de iglesia, estado y letras, Granada: Universidad de Granada, 2011.

Miura Andrades, José María, Frailes, monjas y conventos. Las órdenes mendicantes y la sociedad sevillana bajomedieval, Sevilla: Diputación de Sevilla, 1998.

Nieto Soria, José Manuel, Iglesia y poder real en Castilla. El episcopado. 12501350, Madrid: Universidad Complutense de Madrid, 1988.

- "Franciscanos y franciscanismo en la política y en la corte de la Castilla Trastámara (1369-1475)", Anuario de Estudios Medievales, 20 (1990), pp. 109-128.

- Iglesia y génesis del estado moderno en Castilla (1369-1480), Madrid: Universidad Complutense de Madrid, 1993.

- Sancho IV (1284-1295), Palencia: La Olmeda, 1994.

Nieva Ocampo, "De la colaboración a la oposición: los frailes dominicos y la realeza castellana (1370-1474)", Erasmo: revista de Historia bajomedieval y Moderna, 3 (2016), pp. 89-99.

- La Observancia dominica y la monarquía castellana: compromiso político y disciplinamiento social (1460-1540)", en José Martínez Millán, Concepción Camarero Bullón y Marcelo Luzzi Traficante (coords.), La Corte de los Borbones: crisis del modelo cortesano, vol. 2, Madrid: Polifemo, 2013, pp. 513-562.

Olivares Martínez, Diana y Palomo Fernández, Gema, "Escudos con flor de lis o la huella de un prelado promotor: Alonso de burgos, obispo de Cuenca (14821485)", Lope de Barrientos. Seminario de Cultura, 6 (2013), pp. 93-124.

Palencia, Alonso de, Gesta Hispaniensia ex annalibvs svorvm diervm collecta, Tomo 1. Libri I-V, en Brian Tate y Jeremy Lawrance (ed.), Madrid: Real Academia de la Historia, 1998.

Paul, Jacques, "Les frères Prêcheurs de la province de Provence", en VV. AA. (cords.), L'ordre des Prêcheurs et son histoire en France méridionale, Fanjeaux: Cahiers de Fanjeaux 36-éditions Privat, 2001.

Porras Arboledas, Pedro Antonio, Juan II (1406-1454), Palencia: La Olmeda, 1995. Prieto Sayagués, Juan Antonio, "La función sociopolítica de los monasterios y conventos en las ciudades de Castilla durante los reinados de Juan II y Enrique IV (1406-1474), Roda da Fortuna, volume 4, número 1-1 (2015), pp. 411-437. 
- "El acercamiento de la monarquía castellana a la Orden de los Predicadores durante el reinado de Juan II de Castilla (1406-1454)", En la España Medieval, 39 (2016), pp. 197-224.

- "La relegación de la orden franciscana por parte de la monarquía y su repunte en los ambientes nobiliarios durante el reinado de Juan II de Castilla", en Manuel Pérez del Rosal (coord.), El franciscanismo: identidad y poder. Libro homenaje al P. Enrique Chacón Cabello, OFM, Córdoba: Asociación Hispánica de Estudios Franciscanos-Universidad Internacional de Andalucía, 2016, pp. 819-832.

RAH., Cortes de los antiguos reinos de León y Castilla, Tomo II, Madrid: Imprenta de M. Rivadeneyra, 1863.

RAH., Cortes de los antiguos reinos de León y Castilla, Tomo III, Madrid: Imprenta de M. Rivadeneyra, 1866.

Reglero de la Fuente, Carlos Manuel, Amigos exigentes, servidores infieles. La crisis de la orden de Cluny en España (1270-1379), Madrid: CSIC, 2014.

Revuelta Somalo, Josemaría, Los jerónimos, Guadalajara: Institución Provincial de Cultura "Marqués de Santillana", 1982.

Riesco Terrero, Ángel, Datos para la historia del real convento de clarisas de Salamanca. Catalogo documental e su archivo, León: Centro de Estudios e Investigación San Isidoro, 1977.

Rodriguez Guillén, Santiago, El monasterio de Santa María la Real de Tordesillas (1363-1509), (Tesis Doctoral Inédita), Alcalá de Henares : Universidad de Alcalá de Henares, 2010.

Rodríguez Liañez, Laureano, "El archivo de Santa Inés de Sevilla. Valor y significación de su fondo documental", Archivo Ibero-Americano, no 213-214 (1994), pp. 125-140.

Rodríguez Martínez, Luis, Historia del monasterio de San Benito el Real de Valladolid, Valladolid: Caja de Ahorros Popular de Valladolid-Ateneo de Valladolid, 1981.

Rojo Alique, Francisco Javier, "Intelectuales franciscanos y monarquía en la Castilla medieval", SÉMATA, Ciencias Sociais e Humanidades, vol. 26 (2014), pp. 297318.

Romero Fernández-Pacheco, Juan Ramón, El monasterio de San Jerónimo el Real de Madrid (1464-1510), Madrid: Asociación Cultural Al-Mudayna, 2000.

Salazar y Castro, Luis, Historia genealógica de la Casa de Lara, Tomo I, Madrid: Imprenta Real, 1696, p. 493.

- Historia genealógica de la Casa de Lara, Tomo II, Madrid: Imprenta Real, 1697. Sánchez-Arcilla Bernal, José, Alfonso XI (1312-1350), Palencia: La Olmeda, 1995.

Sancho de Sopranis, Hipólito, "San Francisco el Real de Jerez de la Frontera en el siglo XV. Notas y documentos para su historia", Archivo Ibero-Americano, $\mathrm{n}^{\circ} 5$, 19-20 (1945), pp. 366-404.

Senra Gabriel y Galán, José Luis, "Alfonso XI y Cluny. La restauración de un vínculo tradicional en la primera mitad del siglo XIV", Hispania Sacra, vol. XLVII, $\mathrm{n}^{\circ} 96$ (1995), pp. 537-558.

Sigüenza, José de, Historia de la Orden de San Jerónimo, Tomo I, Valladolid: Junta de Castilla y León, 2000.

Sitges y Grifoll, Juan Blas, Las mujeres del rey don Pedro de Castilla, Madrid: Sucesores de Rivadeneyra, 1910.

Valdeón Baruque, Julio, Enrique II (1369-1379), La Olmeda, Palencia, 1996. 
Vázquez Janeiro, Isaac, "Los Estudios franciscanos medievales en España”, VI Semana de Estudios Medievales de Nájera. Del 31 de julio al 4 de agosto de 1995, Logroño: Instituto de Estudios Riojanos, 1996, pp. 43-64.

Vega y Toraya, Francisco de la, Chronica de la Provincia de Castilla, León y Navarra del orden de la Santíssima Trinidad, Segunda Parte, Madrid: Joseph Rodríguez de Escobar-Impressor del Consejo de la Santa Cruzada, 1723.

Villarroel González, Óscar, "Eclesiásticos al servicio regio en los conflictos urbanos: los casos de Cuenca y Córdoba a mediados del XV", De Medio Aevo, 2014/2, pp. 17-38.

- "Servir al rey en las ligas nobiliarias: los eclesiásticos en las confederaciones políticas", Anuario de Estudios Medievales, 36/2, (2016), pp. 751-781.

VV. AA., Colección diplomática del monasterio de Sahagún (1300-1500), León: Centro de Estudios e Investigación "San Isidoro", 1997.

VV. AA., Diccionario de Historia Eclesiástica de España, vol. 1, Madrid: CSIC, 1972. 